\title{
Impaired adenosine-mediated angiogenesis in preeclampsia: potential implications for fetal programming
}

\author{
Carlos Escudero ${ }^{1}$, James M. Roberts ${ }^{2}$, Leslie Myatt ${ }^{3}$ and Igor Feoktistov ${ }^{4,5}$ \\ ' Vascular Physiology Laboratory, Group of Investigation in Tumor Angiogenesis, Group of Research and Innovation in Vascular Health, Department of Basic \\ Sciences, Faculty of Sciences, Universidad del Bío-Bío, Chillán, Chile \\ ${ }_{2}^{2}$ Magee-Womens Research Institute, Department of Obstetrics, Gynecology, and Reproductive Sciences, Department of Epidemiology and Clinical and \\ Translational Science Institute, University of Pittsburgh, Pittsburgh, PA, USA \\ ${ }^{3}$ Center for Pregnancy and Newborn Research, University of Texas Health Science Center, San Antonio, TX, USA \\ ${ }^{4}$ Division of Cardiovascular Medicine, Department of Medicine, Vanderbilt University, Nashville, TN, USA \\ ${ }^{5}$ Department of Pharmacology, School of Medicine, Vanderbilt University, Nashville, TN, USA
}

\section{Edited by:}

Issy Laher, University of British

Columbia, Canada

\section{Reviewed by:}

Stephen C. Land, University of Dundee, UK

Loren P. Thompson, University of Maryland, Baltimore, USA Norma Beatriz Ojeda, University of Mississippi Medical Center, USA Brett M. Mitchell, Texas A\&M Health Science Center, USA

*Correspondence:

Carlos Escudero, Vascular Physiology Laboratory, Group of Investigation in Tumor Angiogenesis, Group of Research and Innovation in Vascular Health, Department of Basic Sciences, Faculty of Sciences, Universidad del Bío-Bío, Chillán, Chile e-mail: cescudero@ubiobio.cl
Preeclampsia is a pregnancy-specific syndrome, defined by such clinical hallmarks as the onset of maternal hypertension and proteinuria after 20 weeks of gestation. The syndrome is also characterized by impaired blood flow through the utero-placental circulation and relative placental ischemia, which in turn, may generate feto-placental endothelial dysfunction. Endothelial dysfunction in offspring born from preeclamptic pregnancies has been associated with an increased risk of cardiovascular disease, including hypertension, later in life. Interestingly, diminished endothelial function, manifested by low angiogenic capacity, leads to hypertension in animal studies. Recently, we have shown that the adenosine receptor $A_{2 A}$ /nitric oxide/vascular endothelial growth factor axis is reduced in human umbilical vein endothelial cells derived from preeclamptic pregnancies, an effect correlated with gestational age at onset of preeclampsia. We and others suggested that impaired vascular function might be associated with high cardiovascular risk in offspring exposed to pregnancy diseases. However, we are not aware of any studies that examine impaired adenosine-mediated angiogenesis as a possible link to hypertension in offspring born from preeclamptic pregnancies. In this review, we present evidence supporting the hypothesis that reduced adenosine-mediated angiogenesis during preeclamptic pregnancies might be associated with development of hypertension in the offspring.

Keywords: adenosine receptors, angiogenesis, placenta, preeclampsia, programming

\section{INTRODUCTION}

Preeclampsia is a major cause of maternal and infant morbidity and mortality worldwide (Xiong etal., 2002; Duley, 2009). Stillbirth is more common in preeclamptic pregnancies, and one third of infants of preeclamptic women exhibit growth restriction. Furthermore, the appropriate management of preeclampsia (i.e., delivery of women with increasingly severe disease) is responsible for $8 \%$ of preterm births, with attendant increased morbidity and mortality (Sibai et al., 2005; Villar et al., 2006). In the last 30 years, it has become evident that the fetal intrauterine environment has long-lasting consequences for the infant. Low or high birth weight,

\footnotetext{
Abbreviations: NECA, 5'- $N$-ethylcarboxamido-adenosine; AP-1, Activator protein 1; $A R$, adenosine receptor; $A_{2 A} A R$, adenosine receptor $A_{2 A} ; A_{2 B} A R$, adenosine receptor $\mathrm{A}_{2 \mathrm{~B}}$; bFGF, basic fibroblast growth factor; EOPE, early-onset preeclampsia; eNOS, endothelial nitric oxide synthase; EPC, endothelial progenitor cells; hENT1, equilibrative nucleotide transporter type 1 ; hENT2, equilibrative nucleotide transporter type 2; Epac, exchange protein activated by cAMP ; ERK, extracellular signal-regulated kinase; hPMEC, human placental microvascular endothelial cell; HUVEC, human umbilical vein endothelial cell; HIF- $1 \alpha$, hypoxia inducible factor type $1 \alpha$; IL-8, interleukin 8; LOPE, late-onset preeclampsia; MAPK, mitogenactivated protein kinase; LLC, mouse Lewis lung carcinoma; NO, nitric oxide; PKA, protein kinase A; sFlt-1, soluble vascular endothelial growth factor receptor type 1 or soluble fms-like tyrosine kinase-1; sEnd, soluble endoglin; VEGF, vascular endothelial growth factor.
}

prematurity, gestational diabetes, and hypertension not only have an impact on perinatal outcomes; they also have long-term consequences, increasing the risk of neurological disability, obesity, and cardiovascular disease in adult life (Gluckman and Hanson, 2004; Hanson and Gluckman, 2008; Krause etal., 2009). The multiorgan dysfunction syndrome associated with preeclampsia could, directly or indirectly, affect the intrauterine environment.

The underlying pathophysiology of preeclampsia includes dysregulation of endothelial function in both the maternal and the feto-placental circulation (Roberts and Escudero, 2012). Several groups have suggested that long-term complications in offspring from preeclamptic pregnancies might be associated with loss of the endothelium's ability to regulate vascular tone by synthesizing vasoactive molecules. However, the endothelium is also responsible for the generation of new vessels through the process of angiogenesis. Imbalance of angiogenic factors (i.e., reduction in the activity of pro-angiogenic factors in association with high activity/expression of the anti-angiogenic factors) is a well-characterized feature of preeclampsia. The implication of this imbalance for the occurrence of long-term complications in offspring from preeclamptic pregnancies is not yet clear. Since adequate formation of blood vessels is required for controlling blood pressure and for tissue repair, it is likely 
that impaired angiogenesis may contribute to future cardiovascular risk in the newborn "exposed" to preeclampsia in utero.

Adenosine is a naturally occurring nucleoside, which is increased in the feto-placental circulation with preeclampsia (Yoneyama etal., 1996; Escudero etal., 2009; Espinoza et al., 2011). It plays an important role in controlling the production and action of pro-angiogenic factors such as vascular endothelial growth factor (VEGF), as well as anti-angiogenic factors including soluble fms-like tyrosine kinase-1 (sFlt-1; George et al., 2010) and, through this mechanism, may control placental angiogenesis (Escudero et al., 2012). Therefore, it is plausible that dysfunctional adenosine-mediated angiogenesis in utero and after birth may contribute to long-term complications in offspring from preeclamptic pregnancies.

\section{PATHOPHYSIOLOGY OF PREECLAMPSIA: CURRENT HYPOTHESES}

Preeclampsia has been defined by the onset of hypertension and proteinuria after 20 weeks of gestation and is additionally characterized by maternal endothelial dysfunction (Roberts et al., 1989). However, recently The American College of Obstetricians and Gynecologists has stated that proteinuria is no longer absolutely required for diagnosis of preeclampsia (ACOG, Task Force of Hypertension in Pregnancy, 2013). Alternatively, diagnosis may be established by the presence of hypertension associated with thrombocytopenia (platelet count less than $100.000 / \mu \mathrm{L}$ ), impaired liver functions (elevated blood concentrations of liver transaminases up to twice the normal concentration), development of renal insufficiency (serum creatinine concentration greater than $1.1 \mathrm{mg} / \mathrm{dL}$ or a doubling of the serum creatinine concentration in the absence of other renal diseases), pulmonary edema, or new-onset cerebral or visual disturbances.

Current thinking on the pathophysiology of preeclampsia suggests that impaired invasion of trophoblastic cells into the maternal vascular bed leads to aberrant transformation of uterine resistance vessels to large diameter capacitance vessels (Burton et al., 2009a,b). This reduces maternal blood flow to the placenta and generates relative ischemia. Failure to increase the terminal caliber of the spiral arteries results in increased velocity of blood entering the intervillus space, with consequent shear stress on the fetal villus trophoblast (Burton et al., 2009b), leading to cell damage, detachment, and the release of cell fragments into the maternal circulation (Tannetta et al., 2013). These fragments contain elements that may impair maternal endothelial function and generate a vicious cycle that will chronically affect maternal and feto-placental endothelial function.

Among molecules released from the placenta, sFlt-1 has become a focus of study in preeclampsia. It is increased in the blood of women prior to and during clinical preeclampsia and has the potential to blunt angiogenic responses. Importantly, reduction of the plasma level of sFlt-1 in women with preterm preeclampsia using dextran sulfate apheresis has been reported to reduce proteinuria and blood pressure and prolong pregnancy by 23 days without apparent adverse events for mother or fetus
(Thadhani et al., 2011). Moreover, the injection of mice with adenovirus expressing sFlt-1 results in pathophysiological findings resembling preeclampsia (Maynard et al., 2003; Bytautiene et al., 2011; Murphy et al., 2012). This animal model has been employed to study not only the pathophysiology of preeclampsia but also vascular alterations in the offspring (Lu et al., 2007a; Byers et al., 2009; Bytautiene et al., 2011).

\section{DEVELOPMENTAL ORIGINS OF ADULT DISEASE AFTER PREECLAMPSIA}

The fetal programming hypothesis proposes that chronic diseases may originate through adaptations of the fetus to an adverse intrauterine environment. These adaptations may include changes in the vascular, metabolic, or endocrine systems. Those changes permanently affect function in adult life.

Numerous epidemiological studies suggest an important role for the adverse intrauterine environment in the development of schizophrenia, depression, cardiovascular diseases, stroke, diabetes, cancer, pulmonary hypertension, osteoporosis, polycystic ovarian syndrome, and other conditions in adult life. These observational relationships are supported by animal experiments in which effects on fetal growth via manipulation of maternal nutrition or reduction of blood flow to the placenta (by various approaches) result in obesity, increased blood pressure, and other cardiovascular abnormalities in the offspring later in life (Hanson and Gluckman, 2008; Glover, 2011; Davis et al., 2012b). Applying this concept to preeclampsia brings in a number of other insults which may trigger programming. These include increased oxidative stress and elevated concentration of anti-angiogenic factors, which can also result in growth restriction or premature deliveries.

\section{PREECLAMPSIA AND LONG-TERM ADVERSE OUTCOMES IN THE OFFSPRING}

Many epidemiological studies (Kajantie et al., 2009; Wu et al., 2009, 2011; Davis et al., 2012a,b; Lawlor et al., 2012) indicate that preeclampsia is associated with long-term adverse outcomes in the offspring. The majority of studies (Palti and Rothschild, 1989; Seidman et al., 1991; Tenhola et al., 2003, 2006; Vatten et al., 2003; Swarup et al., 2005; Hiller et al., 2007; Oglaend et al., 2009; Kvehaugen et al., 2010; Lazdam et al., 2010; Palmsten et al., 2010; Lawlor et al., 2012), but not all (Ounsted et al., 1983; Jayet et al., 2010; Belfort et al., 2012; Lawlor et al., 2012) report that children and adolescents who were exposed to preeclampsia or hypertension in pregnancy exhibit higher systolic and diastolic blood pressure compared with non-exposed children or adolescents. These studies were reviewed in a recent meta-analysis (Davis et al., 2012a), which included individuals aged 4-30 years, born at term from preeclamptic pregnancies. This meta-analysis concluded that offspring born from preeclamptic women had $\sim 2 \mathrm{~mm} \mathrm{Hg}$ greater systolic and $\sim 1.3 \mathrm{~mm} \mathrm{Hg}$ greater diastolic blood pressure than individuals born from normotensive pregnancies. Interestingly, according to their prediction, "if the $2.4 \mathrm{mmHg}$ difference in systolic blood pressure tracks into adulthood (Chen and Wang, 2008), this difference would be associated with an $\sim 8 \%$ increased risk of mortality from ischemic heart disease and $12 \%$ increased risk from stroke" (Davis et al., 2012a). Based on a study in a large population of preeclamptic pregnancies, Kajantie et al. (2009) reported that 
the risk for stroke in subjects born from preeclamptic pregnancies was twice that of controls born from normotensive pregnancies. Other studies have described an increased risk for pulmonary hypertension (Jayet et al., 2010), metabolic and endocrine disease (Wu et al., 2009, 2011), depression (Tuovinen et al., 2010), cerebral palsy (Szymonowicz and Yu, 1987), poor cognitive outcome (Cheng et al., 2004), or intellectual disabilities (Griffith et al., 2011) in children born of preeclamptic pregnancies compared to non-exposed children.

These clinical and epidemiological observations are supported by a recent review of animal models of preeclampsia (Davis et al., 2012b), including those generated by systemic hypoxia, by mechanical reduction of maternal uterine artery blood flow, in genetically modified animals lacking endothelial nitric oxide synthase (eNOS), or by overexpression of sFlt-1 by infection with adenovirus carrying this protein. Notwithstanding differences in design and outcome of these models, the conclusion was that "animal studies support the potential relevance of these insults to programming of offspring blood pressure."

Although fetal programming by preeclampsia is suggested by human and animal studies, it is not easy to determine whether preeclampsia per se leads to high cardiovascular risk in the offspring or whether related factors, such as intrauterine growth restriction or preterm delivery, contribute. To allay these concerns, most studies have excluded individuals exposed to preterm delivery or intrauterine growth restriction associated with preeclampsia. Interestingly, the risks for hypertension, impaired neurological function, and stroke in offspring from preeclamptic pregnancies remain significant (Kajantie etal., 2009; Tuovinen et al., 2010, 2012). Moreover, a study performed in brothers exposed, or not, to preeclampsia suggested that impaired vessel function was associated with preeclampsia per se rather than genetic predisposition (Jayet et al., 2010). It is plausible, then, that exposure to preeclampsia in utero can predispose to adverse outcomes later in life.

Understanding the underlying mechanisms might suggest interventions to prevent the occurrence of future chronic disease in offspring exposed to preeclampsia. Several groups (Jayet et al., 2010; Lazdam et al., 2010; Kvehaugen et al., 2011; Davis etal., 2012a,b; Lawlor etal., 2012), including ours (Escudero and Sobrevia, 2008; Escudero et al., 2012), have presented evidence of endothelial dysfunction in the feto-placental circulation in preeclampsia, which may be a precursor to the longterm complications observed in offspring born of preeclamptic pregnancies.

\section{ENDOTHELIAL DYSFUNCTION AND IMPAIRED ANGIOGENESIS IN OFFSPRING BORN FROM PREECLAMPTIC PREGNANCIES}

Endothelial dysfunction is a pathological state characterized by an imbalance between vasodilators and vasoconstrictors produced by (or acting on) the endothelium (Brunner et al., 2005). Infants born of preeclamptic pregnancies have evidence of endothelial dysfunction shortly after delivery and months to years later (Davis et al., 2012a,b; Sobrevia et al., 2012; Wadsack et al., 2012). For instance, reduced flow-mediated vasodilatation (a hallmark of endothelial dysfunction) has been reported in children born from preeclamptic pregnancies as compared to children born from normotensive pregnancies (Jayet et al., 2010; Lazdam etal., 2010; Kvehaugen et al., 2011; Davis et al., 2012b). In animal studies using mice, male offspring born from mothers with preeclamptic-like syndrome, generated by administration of adenovirus carrying sFlt-1, exhibited high blood pressure (Lu et al., 2007a,b) and increased vascular reactivity (Byers etal., 2009; Bytautiene et al., 2011) compared to controls.

It is also clear that endothelial cells are main contributors to angiogenesis (Shibuya, 2006; Escudero et al., 2009), which leads to the growth of new blood vessels from pre-existing ones. The endothelium participates in angiogenesis through several processes, which include cell proliferation/migration, tube formation, as well as synthesis and release of pro-angiogenic factors including VEGF (Shibuya, 2013). In addition, neovasculogenesis, a process of blood vessel formation occurring by de novo production of endothelial cells, can occur not only at the embryonic stage but also in adult life (Risau, 1997). Endothelial progenitor cells (EPCs) play a critical role in postnatal blood vessel formation and vascular homeostasis. In preeclampsia, impaired feto-placental angiogenesis (Escudero et al., 2009, 2012, 2014) and neovasculogenesis (due to the reduced number of EPCs found in umbilical cord blood (Kwon et al., 2007; Xia et al., 2007; Monga et al., 2012) may be a result of endothelial dysfunction.

Reduced placental levels of several pro-angiogenic factors have been reported in the feto-placental circulation in early-onset preeclampsia (EOPE) when these are compared to late-onset preeclampsia (LOPE) or to age-matched controls (Gellhaus et al., 2006; Junus et al., 2012). Microarray analysis reveals lower expression of at least two angiogenesis-associated transcripts (Egfl7 and Acvrl1) in EOPE compared to LOPE or age-matched controls (Junus etal., 2012). Recently, we have reported that the proliferation/migration of human umbilical vein endothelial cells (HUVEC) is reduced in EOPE compared to LOPE or controls, whereas cells from LOPE exhibit elevated proliferation/migration compared to controls (Escudero et al., 2012). These reports suggest that angiogenesis could be modified in the feto-placental circulation in preeclampsia.

The mechanisms underlying impaired neovascularization in feto-placental circulation during preeclampsia are under investigation and may be associated with the reduced numbers of EPCs observed in umbilical blood (Kwon et al., 2007; Xia et al., 2007; Monga etal., 2012), an increase in circulating anti-angiogenic factors such as sFlt-1 (Staff et al., 2005; Tsao et al., 2005) and soluble endoglin (sEnd; Staff et al., 2007), or reduced expression and activity of pro-angiogenic signals such as VEGF (Lyall et al., 1997; Andraweera et al., 2012; Kim et al., 2012) or adenosine (Escudero etal., 2012). As presented in Figure 1, this imbalance is manifested mainly by elevation of sFlt-1and sEnd, associated with reduced numbers of EPCs, which may nullify pro-angiogenic signals from VEGF and placental growth factor (PlGF).

Several prior studies have examined feto-placental tissue; however, few studies (see for instance Staff et al., 2005; Tsao et al., 2005; Kvehaugen et al., 2010, 2011) have assessed endothelial dysfunction postnatally in newborn infants or children exposed to 


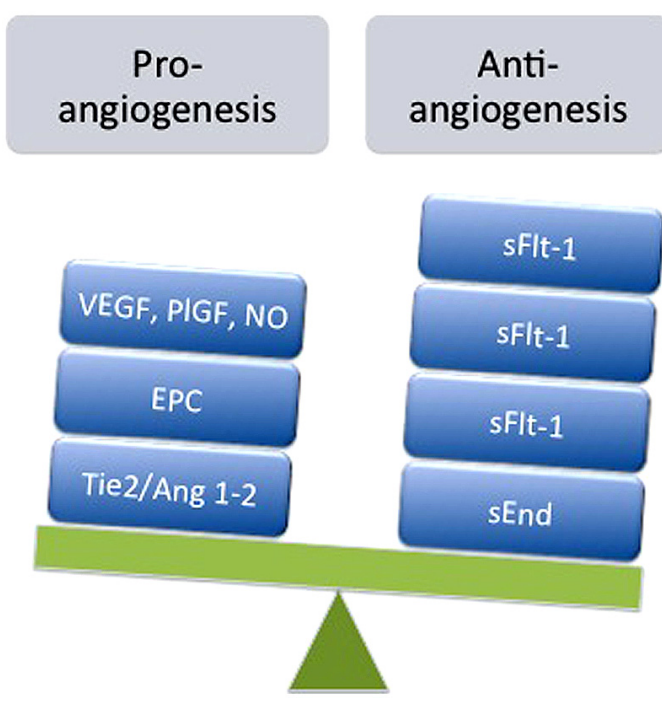

FIGURE 1 | Imbalance of pro- and anti-angiogenesis in feto-placental circulation during preeclampsia. Represented is the reduction in expression and/or action of pro-angiogenic factors such as vascular endothelial growth factor (VEGF), placental growth factor (PIGF), adenosine, nitric oxide (NO), angiopoietin 1 (Ang1) and 2 (Ang2), and angiopoietin tyrosine kinase (Tie2), as well as reduction in the number of endothelial progenitor cells (EPC) exhibited in umbilical blood derived from preeclamptic pregnancies. On the other hand, elevated levels of anti-angiogenic factors such as soluble receptor type 1 of VEGF (sFlt-1) and soluble endoglin receptor (sEnd) have been also reported in umbilical circulation from preeclampsia.

preeclampsia. Considering that placental blood vessels on the fetal side form a continuous network with fetal systemic circulation, it is pertinent to ask whether offspring exposed to preeclampsia exhibit endothelial dysfunction and impaired angiogenesis after birth.

To the best of our knowledge, there is no direct answer to this question. However, indirect evidence includes increased concentrations of sFlt-1 in the fetus from preeclamptic pregnancies as measured in umbilical cord blood (Staff et al., 2005; Tsao et al., 2005). Offspring with high blood pressure whose parents also had high blood pressure showed fewer capillaries in the dorsum of the finger compared with either offspring with low blood pressure whose parents were either normotensive or hypertensive or hypertensive offspring whose parents were normotensive (Noon et al., 1997). More recently, Yu et al. (2012) reported that children born from preeclamptic pregnancies exhibited a $45 \%$ reduction in the risk of retinopathy of prematurity, a well-described example of pathological angiogenesis in premature infants, compared to preterm babies born from normotensive pregnancies. Moreover, Stark et al. (2009), studying blood flow immediately after birth in the microcirculation of children born from preeclamptic pregnancies, found altered fetal microvascular structure and function, particularly in male newborns.

In animal studies, at postnatal day 7 , rat pups from spontaneously hypertensive mothers, exposed to hypoxic-ischemic brain injury, exhibited less brain damage than pups from normotensive mothers (Letourneur et al., 2012). Interestingly, this apparently protective phenomenon was associated with deficits in motor coordination and spatial learning in pups from hypertensive, compared to normotensive mothers. These results could be interpreted as a consequence of impaired angiogenesis. This could reduce the area of the lesion but also impair tissue recovery after ischemic insult in the brain. Therefore, it is plausible that offspring born from preeclamptic pregnancies may exhibit reduced angiogenic processes after birth, which may lead to cardiovascular complications later in life.

The latter concept is supported by the following findings: (1) VEGFR2 gene expression decreases with development (Greene et al., 2011). Also, vessel branching in the brain increases until 10 days postpartum and stabilizes to adult levels between days 10 and 25 in mice (Harb et al., 2013); (2) mature (4-5 month old) mouse brains lose their ability to undergo angiogenesis in response to hypoxia (Harb et al., 2013), suggesting that the process of angiogenesis, even in stressful conditions, is limited after birth; (3) VEGF production and activity are both impaired in the feto-placental circulation during preeclampsia (Lyall et al., 1997; Andraweera et al., 2012; Kim et al., 2012); (4) Inhibition of angiogenesis with humanized antibodies targeting VEGF or orally active small tyrosine kinase inhibitors targeting VEGF receptors is commonly associated with severe hypertension (Lankhorst et al., 2013); (5) Loss of microvessel growth has been reported to precede elevations in blood pressure (Murfee and Schmid-Schonbein, 2008); (6) Programming of elevated blood pressure in the offspring has been associated with a reduced angiogenic capacity of vessels cultured in vitro (Pladys et al., 2005). Taking all these data into account, we believe that abnormal angiogenic processes present after birth in offspring born from preeclamptic pregnancies may contribute to elevation in blood pressure later in life.

\section{OVERVIEW OF ADENOSINE RECEPTORS ADENOSINE RECEPTORS AND ANGIOGENESIS}

Adenosine is a purinergic nucleoside which controls several physiological processes, including angiogenesis and vasculogenesis. Adenosine activates a family of $\mathrm{G}$-coupled adenosine receptors, $\mathrm{A}_{1} \mathrm{AR}, \mathrm{A}_{2 \mathrm{~A}} \mathrm{AR}, \mathrm{A}_{2 \mathrm{~B}} \mathrm{AR}$, and $\mathrm{A}_{3} \mathrm{AR}$ (Olah and Stiles, 2000; Jacobson and Gao, 2006). All of the adenosine receptors have been implicated in the modulation of angiogenesis (see Table 1). Briefly, stimulation of $\mathrm{A}_{1} \mathrm{AR}$ on embryonic EPCs promotes their adherence to the vascular endothelium, suggesting an important role for this receptor subtype in vasculogenesis (Ryzhov et al., 2008). $\mathrm{A}_{1} \mathrm{AR}$ have also been reported to upregulate VEGF production from monocytes, thus promoting angiogenesis (Clark et al., 2007).

Depending on the tissue or cell studied, $\mathrm{A}_{2 \mathrm{~A}} \mathrm{AR}$ and $\mathrm{A}_{2 \mathrm{~B}} \mathrm{AR}$ can play a dominant role in the regulation of angiogenic factors. For example, $\mathrm{A}_{2 \mathrm{~B}} \mathrm{AR}$ upregulates the pro-angiogenic factors VEGF, basic fibroblast growth factor (bFGF), insulinlike factor-1, and interleukin 8 (IL-8) in human microvascular endothelial cells (Grant et al., 1999; Feoktistov et al., 2002). Conversely, $\mathrm{A}_{2 \mathrm{~A}} \mathrm{AR}$ is reported to upregulate VEGF in macrophages (Leibovich et al., 2002; Pinhal-Enfield et al., 2003). Stimulation of $\mathrm{A}_{3} \mathrm{AR}$ in mast cells and some tumors can result in upregulation of pro-angiogenic factors, complementing the actions of adenosine mediated via $\mathrm{A}_{2 \mathrm{~B}} \mathrm{AR}$ (Feoktistov et al., 2003). Of interest, 
stimulation of $\mathrm{A}_{2 \mathrm{~A}} \mathrm{AR}$ in HMEC-1 inhibits the release of the antiangiogenic factor thrombospondin 1 , providing yet another means by which adenosine may regulate angiogenesis (Desai et al., 2005; see Table 1).

While $A_{2 A} A R$ and $A_{2 B} A R$ have been shown to mediate the proliferative actions of adenosine in human retinal microvascular endothelial cells (Grant et al., 1999, 2001), HUVEC (Feoktistov et al., 2004; Escudero et al., 2012), or porcine coronary artery and rat aortic endothelial cells (Dubey et al., 2002), it remains unclear whether $\mathrm{A}_{1} \mathrm{AR}$ and $\mathrm{A}_{3} \mathrm{AR}$ are functionally expressed and what role, if any, they play in endothelial cells (Wyatt et al., 2002; Schaddelee et al., 2003).

\section{ADENOSINE RECEPTORS AND INTRACELLULAR PATHWAYS DURING ANGIOGENESIS}

Although some data suggest that cAMP may play a role in the pro-angiogenic effects of adenosine in certain cells (Takagi et al., 1996), other studies show that upregulation of angiogenic factors is mediated via coupling to Gq, possibly involving mitogenactivated protein kinase (MAPK) pathways (Grant et al., 1999,
2001; Feoktistov et al., 2002; Ryzhov et al., 2014). Further studies, using HMEC-1 demonstrated that adenosine receptor-dependent upregulation of VEGF production was associated with an increase in VEGF transcription, activator protein 1 (AP-1) activity and transcription factor JunB (JunB) accumulation (Ryzhov et al., 2014).

Mechanistically, $A_{2 B} A R$ which are coupled to both $G$ s and Gq proteins (Feoktistov and Biaggioni, 1995) increase JunB protein levels and VEGF production via stimulation of protein lipase $\mathrm{C}$ and extracellular signal-regulated kinase (ERK), which are possibly linked by the calcium diacylglycerol guanine nucleotide exchange factor (CalDAG-GEF)-Ras-proximate-1 (Rap1) pathway (Ryzhov et al., 2014). These effects were protein kinase A (PKA)-independent because the PKA inhibitors had no effect on the $A_{2 B} A R$-dependent increase in JunB protein levels and VEGF production. Because VEGF secretion and reporter promoter activity induced by the adenosine ana$\log 5^{\prime}$-N-ethylcarboxamido-adenosine (NECA) were inhibited by the expression of a dominant, negative JunB or by JunB knockdown, these data suggest an important role for the $A_{2 B}$

Table 1 | Summary of participation of adenosine receptor in angiogenesis using human cells.

\begin{tabular}{|c|c|c|c|c|}
\hline AR & $K_{\mathrm{d}}(\mathrm{nM})$ & Angiogenic process & Cell type & Reference \\
\hline$A_{1}$ & $3-30$ & 仓 Migration & EPC & Ryzhov et al. (2008) \\
\hline \multirow[t]{5}{*}{$A_{2 A}$} & $1-20$ & 仓VEGF expression & Macrophages & Pinhal-Enfield etal. (2003), Ernens et al. (2010) \\
\hline & & $\boldsymbol{\Downarrow}$ Thrombospondin 1 expression & HMVEC & Desai etal. (2005) \\
\hline & & $\downarrow$ sFlt-1 release & Macrophages & Leonard et al. (2011) \\
\hline & & 仓 mFlt-1 expression & Macrophages & Leonard et al. (2011) \\
\hline & & 仓 Proliferation/migration and VEGF expression & HUVEC & Escudero etal. (2012) \\
\hline \multirow[t]{10}{*}{$A_{2 B}$} & $5.000-20.000$ & 仓 Permeability & HUVEC-PMN & Lennon et al. (1998) \\
\hline & & 仓VEGF expression & HMVEC & Ryzhov etal. (2014) \\
\hline & & 仓 Migration & HREC & Afzal et al. (2003) \\
\hline & & 仓VEGF, IL-8 and bFGF expression & HMEC-1 & Feoktistov et al. (2002) \\
\hline & & 仓 Migration & EPC & Rolland-Turner et al. (2013) \\
\hline & & 仓 VEGF and IL-8 expression & Foam cell & Gessi et al. (2010) \\
\hline & & 仓 IL-8 secretion & Melanoma cells, HT29 & Merighi et al. (2007, 2009) \\
\hline & & 仓VEGF expression & HUVEC under hypoxia & Feoktistov et al. (2004) \\
\hline & & 仓 VEGF and IL-8 expression & HMEC-1 & Feoktistov et al. (2003) \\
\hline & & $\begin{array}{l}\text { 仓 Proliferation/migration and tube formation } \\
\text { and VEGF expression }\end{array}$ & HREC & Grant etal. (1999, 2001) \\
\hline \multirow[t]{5}{*}{$A_{3}$} & $>1.000$ & $\downarrow$ Migration and tube formation & HUVEC & Kim et al. (2013) \\
\hline & & 仓 VEGF and IL-8 expression & Foam cell & Gessi et al. (2010) \\
\hline & & 仓 VEGF and IL-8 expression & Melanoma cells & Merighi et al. (2009) \\
\hline & & 仓 VEGF expression & HT29 & Merighi et al. (2007) \\
\hline & & 仓 Angiopoietin-2 expression & HMEC-1 & Feoktistov et al. (2003) \\
\hline
\end{tabular}

$K_{d}(n M)$ for adenosine. VEGF, vascular endothelial growth factor; sFlt-1, soluble; mFlt-1, membrane-linked receptor type 1 for VEGF; IL-8, Interleukin 8; bFGF, basic

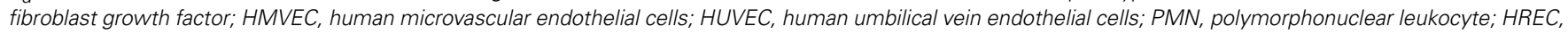

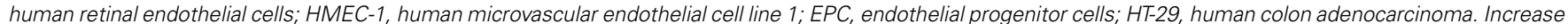
(仓) and decrease ( $\mathbf{\Downarrow})$ of pro or anti-angiogenic processes; AR, adenosine receptor. 
receptor-dependent upregulation of JunB in VEGF production in various cell types, including endothelial cells (Ryzhov et al., 2014).

Another study, in HUVEC, reported that adenosine-mediated activation of ERK may involve an exchange protein activated by cAMP (Epac), a component of a family of cAMP-activated guanine nucleotide exchange factors for Rap GTPases (Fang and Olah, 2007). Thus, $A_{2 B} A R$, coupled to $G \alpha_{s}$ promotes activation of adenylyl cyclase and an increase in intracellular cAMP. In turn, cAMP activates Epac 1, which may then activate a cascade of RapGTPase, B-Raf, and finally, ERK (Fang and Olah, 2007), demonstrating an alternative pathway for ERK activation involved in upregulation of pro-angiogenic proteins.

In addition to JunB, the mediators downstream of ERK and p38 MAPK activation may include molecules such as hypoxia inducible factor type $1 \alpha(\mathrm{HIF}-1 \alpha)$ and/or nitric oxide (NO). Using foam cells generated in vitro, Gessi et al. (2010) found that activation of $\mathrm{A}_{3} \mathrm{AR}, \mathrm{A}_{2 \mathrm{~B}} \mathrm{AR}$, and to a lesser extent, the $\mathrm{A}_{2 \mathrm{~A}}$ subtypes were associated with the production of VEGF induced by adenosine and hypoxia. This last effect was dependent on activation of ERK, p38 MAPK, Akt, and HIF-1 $\alpha$. Furthermore, adenosine has been reported to increase the synthesis of the angiogenic modulator NO in some, but not all, cultured endothelial cells (Sobrevia et al., 1996; Li et al., 1998; Wyatt et al., 2002). Whether, adenosine receptor-mediated activation of ERK-MAPK-HIF- $1 \alpha$ increases NO is unknown. But, it has been reported that NO promotes a regulatory loop with ERK activation/deactivation (Schieke et al., 1999) and stabilization of HIF- $1 \alpha$ and promotes HIF- $1 \alpha$ binding to DNA (Kimura et al., 2000).

\section{EXPRESSION OF ADENOSINE RECEPTORS IN ENDOTHELIAL CELLS DURING HYPOXIA}

The expression of adenosine receptor subtypes and their function are subject to dynamic regulation by hypoxia (Bshesh et al., 2002; Eltzschig etal., 2003; Feoktistov et al., 2004). Because the $\mathrm{A}_{2 \mathrm{~B}} \mathrm{AR}$ promoter contains a functional binding site for HIF$1 \alpha$ (Kong etal., 2006), the onset of hypoxia strongly induces $\mathrm{A}_{2 \mathrm{~B}} \mathrm{AR}$ expression in different cell types including human dermal microvascular endothelial cells (Eltzschig et al., 2003), and HUVEC (Feoktistov et al., 2004). In addition, elevated expression of $\mathrm{A}_{2 \mathrm{~A}} \mathrm{AR}$ has also been reported after exposure to hypoxia in human placental homogenate (Von Versen-Hoynck et al., 2009), fetal chromaffin-derived cell line (Brown et al., 2011), and human lung endothelial cells, while no evidence of $\mathrm{A}_{2 \mathrm{~A}} \mathrm{AR}$ upregulation was seen in mouse endothelial cells (Ahmad et al., 2009).

Interestingly, despite the fact that all adenosine receptors contain a hypoxia response element in their promoters (St. Hilaire et al., 2009), regulation via HIF is differentially modulated. Whereas $A_{2 B} A R$ is regulated by $\mathrm{HIF}-1 \alpha, A_{2 A} A R$ is regulated by $\mathrm{HIF}-2 \alpha$, suggesting that transcriptional regulation might be part of the switch of $A_{2 A} A R$ toward $A_{2 B} A R$ expression observed in HUVEC exposed to hypoxia (Feoktistov et al., 2004). This switch may have important functional implications for regulation of angiogenesis. For example, in HUVEC, adenosine does not stimulate VEGF secretion under normoxic conditions, but hypoxia increases the expression of $\mathrm{A}_{2 \mathrm{~B}} \mathrm{AR}$, which are then able to stimulate VEGF release (Feoktistov et al., 2004). Therefore, we could speculate that switching the expression of adenosine receptor toward $A_{2 B} A R$ rather than $A_{2 A} A R$ during hypoxia in the endothelium may offer some advantages in the angiogenic process, since high levels of adenosine may downregulate activation and/or expression of $\mathrm{A}_{2 \mathrm{~A}} \mathrm{AR}$ as mechanisms of desensitization. But at the same time, upregulation of $A_{2 B} A R$ will enhance or maintain the pro-angiogenic capacity of adenosine in conditions were high levels of this autocoid are expected. It is likely that this phenomenon may occur in preeclampsia.

\section{ADENOSINE, ANGIOGENESIS, AND PREECLAMPSIA ADENOSINE LEVELS DURING PREECLAMPSIA}

The plasma level of adenosine is finely regulated by a series of enzymes responsible for synthesis and catabolism (see details in Escudero and Sobrevia, 2009). Compared with non-pregnant women, normal, pregnant women exhibit increased synthesis, but reduced catabolism, of adenosine (Yoneyama et al., 2000; Lee et al., 2007). Several studies have described high adenosine levels in both maternal (Yoneyama et al., 2001, 2002a,b,c) and fetal blood (Yoneyama etal., 1996; Espinoza et al., 2011; Escudero and Sobrevia, 2012) during preeclampsia, particularly in severe preeclampsia, compared with normal pregnancies (Yoneyama et al., 1996; Espinoza et al., 2011; Escudero and Sobrevia, 2012). Unexpectedly, these high levels are associated with high adenosine catabolism via adenosine deaminase 2 (ADA2; Yoneyama et al., 2002a; Kafkasli et al., 2006) as well as elevated adenosine uptake (Escudero et al., 2008). The causes and consequences of a high extracellular adenosine level in both maternal and fetal circulation during preeclampsia are unclear; however, it may be explained by an adaptive mechanism (Casanello et al., 2007; Escudero and Sobrevia, 2008, 2009, 2012; Escudero et al., 2009) associated with vasodilation or angiogenesis in preeclamptic placenta as occurs in other tissues, such as heart, muscle, or brain, in unfavorable conditions such as hypoxia (Eckle et al., 2007; Loffler et al., 2007).

The levels of adenosine in umbilical vein blood in preeclampsia ( 1.7 vs. $0.5 \mu \mathrm{mol} / \mathrm{L}$, preeclampsia vs. normal pregnancy; Yoneyama etal., 1996; Espinoza etal., 2011) and in the culture medium of human placental microvascular endothelial cells (hPMEC) from preeclamptic pregnancies (2.7 vs. $0.6 \mu \mathrm{mol} / \mathrm{L})$ are at least three times higher than in normal pregnancy (Escudero et al., 2008), making it likely that, in preeclampsia, all adenosine receptors are likely to be stimulated (Jacobson and Gao, 2006). However, only a few reports have described the effect of preeclampsia on the expression and function of adenosine receptors (Escudero et al., 2008, 2012; Kim etal., 2008; Von VersenHoynck et al., 2009). Thus, reduced expression of $A_{2 A} A R$, without changes in $\mathrm{A}_{2 \mathrm{~B}} \mathrm{AR}$ (Escudero et al., 2008), was found in hPMEC isolated from preeclamptic placentas, whereas reduced $\mathrm{A}_{2 \mathrm{~A}} \mathrm{AR}$ (Escudero et al., 2012) but higher $\mathrm{A}_{2 \mathrm{~B}} \mathrm{AR}$ (Acurio et al., 2014) expression levels were found in HUVEC from preeclampsia. Yet, increased levels of all adenosine receptors have been reported in placental homogenate from preeclamptic placentas 
compared with normal pregnancy (Von Versen-Hoynck et al., 2009).

\section{ADENOSINE RECEPTOR ACTIVATION IN PREECLAMPSIA}

It has been shown that activation of $A_{2 A} A R$ leads to reduction in adenosine uptake by the equilibrative nucleotide transporter type 1 (hENT1) and hENT2, whereas $\mathrm{A}_{2 \mathrm{~B}} \mathrm{AR}$ activation increases hENT2-mediated adenosine transport in cells from preeclamptic placentas (Escudero et al., 2008). Therefore, during preeclampsia, activation of adenosine receptors may control adenosine transport and, hence, extracellular adenosine levels. However, because adenosine levels are increased despite the elevation of total adenosine uptake, it is expected that the production of adenosine from sources such ATP or cell debris is higher in preeclampsia than in normal pregnancy (Spaans et al., 2014).

Recently, we observed reduced protein abundance of $A_{2 A} A R$ in HUVEC derived from EOPE, but non-significant changes in LOPE, compared with cells from normal pregnancy. These findings were associated with a basal (i.e., without any treatment) reduction in cell migration/proliferation of HUVEC in EOPE compared with normal pregnancy or LOPE (Escudero et al., 2012). In addition, CGS-21680 (an $\mathrm{A}_{2 \mathrm{~A}} \mathrm{AR}$ agonist) and NECA significantly increased HUVEC migration/proliferation in normal pregnancy, LOPE, and EOPE. However, considering that cells from EOPE exhibited the lowest migration/proliferation in the basal conditions, the magnitude of response to both adenosine receptor agonists in migration and proliferation tends to be higher in cells from EOPE than those from others groups. In agreement with these results, VEGF expression was significantly lower in HUVEC from EOPE, but higher in LOPE, compared to normal pregnancy. Also, CGS-21680 increases the protein abundance of VEGF in normal and EOPE-derived cells, an effect blocked by the $A_{2 A} A R$ antagonist ZM-241385. Nevertheless, CGS-21680 did not affect VEGF expression in HUVEC from LOPE, but ZM241385 led to a reduction $(41 \pm 6 \%, p<0.05)$ in the level of this protein compared to corresponding levels at basal condition, suggesting that $\mathrm{A}_{2 \mathrm{~A}} \mathrm{AR}$ is activated at basal condition in LOPE. Thus, $\mathrm{A}_{2 \mathrm{~A}} \mathrm{AR}$-mediated HUVEC proliferation and migration was associated with VEGF synthesis in normal pregnancy, LOPE, and EOPE.

To elucidate potential intracellular pathways related to $A_{2 A} A R$ activation, we determined that CGS-21680 increased the synthesis of NO as evidenced by activation of eNOS (i.e., the p-eNOS/eNOS ratio) and nitrite and nitrotyrosine levels in HUVEC from normal pregnancies and EOPE, but not in LOPE. The stimulatory effect observed in normal and EOPE cells was blocked by ZM241385 co-incubation. In contrast, ZM-241385 reduced NO synthesis in LOPE cells compared to non-treated controls. Furthermore, using the non-selective nitric oxide synthase inhibitor, L-NAME, we found a significant reduction in the HUVEC migration/proliferation responses and VEGF protein levels in cells from normal pregnancies and LOPE, but not in EOPE cells stimulated with CGS-21680.

Thus, our study demonstrated that activation of $\mathrm{A}_{2 \mathrm{~A}} \mathrm{AR}$ is associated with the following cascade: eNOS activation (i.e., ser ${ }^{1177}$ phosphorylation), NO synthesis, nitrotyrosine formation, VEGF expression, and cell proliferation/migration in normal pregnancy. However, cells derived from EOPE and LOPE were different in several aspects. Whereas EOPE cells exhibited low $\mathrm{A}_{2 \mathrm{~A}} \mathrm{AR}$ expression and reduction of NO/VEGF synthesis and cell proliferation/migration; LOPE cells demonstrated increased cell proliferation/migration, mediated in part through the same pathway (see Figure 2). Existence of this pathway was recently confirmed using selective shRNA for $\mathrm{A}_{2 \mathrm{~A}} \mathrm{AR}$ in HUVEC. Knockdown of $A_{2 A} A R$ was associated with reduced formation of intracellular cAMP, NO metabolites, VEGF protein level, and the capacity for tube formation compared with controls (unpublished results).

As stated before, adenosine-dependent angiogenesis can be regulated by all four adenosine receptors. There is little information on the role of $\mathrm{A}_{2 \mathrm{~B}} \mathrm{AR}$ in the angiogenic process during preeclampsia, whereas the participation of $A_{1} A R$ and $A_{3} A R$ in this process is unknown. In primary cultures of hPMEC, a cell type with high pro-angiogenic capacity compared to HUVEC (Dye et al., 2004), we found that $\mathrm{A}_{2 \mathrm{~B}} \mathrm{AR}$ may be constitutively activated in cells from preeclamptic placentas, since the use of $\mathrm{A}_{2 \mathrm{~A}} / \mathrm{A}_{2 \mathrm{~B}} \mathrm{AR}$ inhibitors in non-stimulated cells decreases adenosine uptake (Escudero et al., 2008). More recently, we found that activation of $A_{2 B} A R$ in HUVEC accounts for at least $30 \%$ of the pro-proliferative response mediated by adenosine or NECA (Acurio et al., 2014). These data agree with prior reports (Feoktistov et al., 2002, 2004) that exposure of HUVEC to hypoxia increases the expression of $A_{2 B} A R$, which is then able to stimulate VEGF release.

\section{HYPOTHESIS FOR A ROLE FOR ADENOSINE IN PREECLAMPSIA}

In view of available information, we can speculate that during preeclampsia, a condition associated with reduction in the expression and activity of $\mathrm{A}_{2 \mathrm{~A}} \mathrm{AR}$, a compensatory increase in the expression and/or activity of $\mathrm{A}_{2 \mathrm{~B}} \mathrm{AR}$ occurs that tends to compensate the impaired adenosine-mediated pro-angiogenic process. Moreover, since adenosine is pro-angiogenic, the reduction in $\mathrm{A}_{2 \mathrm{~A}} \mathrm{AR}$ expression and down activation of $\mathrm{A}_{2 \mathrm{~A}} \mathrm{AR}$-dependent intracellular pathway might be part of the apparent "adenosine paradox," in which increased adenosine levels do not stimulate angiogenesis in preeclampsia. The mechanism underlying this phenomenon is unclear, but may be associated with the capacity of adenosine to regulate the expression of its receptors, as exhibited in cells such as cardiomyocytes (Headrick et al., 2013) or PC12 cells (Saitoh et al., 1994). In particular, PC12 exposure to $A_{2 A} A R$ agonists reduces ADORA2 gene expression (Saitoh et al., 1994), suggesting a transcriptional regulation of $\mathrm{A}_{2 \mathrm{~A}} \mathrm{AR}$ by adenosine. Whether similar regulation is present in endothelium is unknown, but this is a possible mechanism for the pathophysiological deregulation observed in preeclampsia.

Although the intracellular signaling pathway related to adenosine receptor activation is an area of active research, only our recent study suggested a potential adenosine receptor-dependent mechanism in preeclampsia. On the basis of this study, we propose a model (Figure 2), in which low expression of $\mathrm{A}_{2 \mathrm{~A}} \mathrm{AR}$ in EOPE leads to reduction in NO and VEGF expression (Escudero et al., 2012). The implication of these alterations for feto-placental angiogenesis is poorly understood, but might involve changes in the activation of HIF (Kimura etal., 2002) and changes in the promoter activity of several proteins, including anti-angiogenic factors such as thrombospondin 2 (MacLauchlan et al., 2011) or 


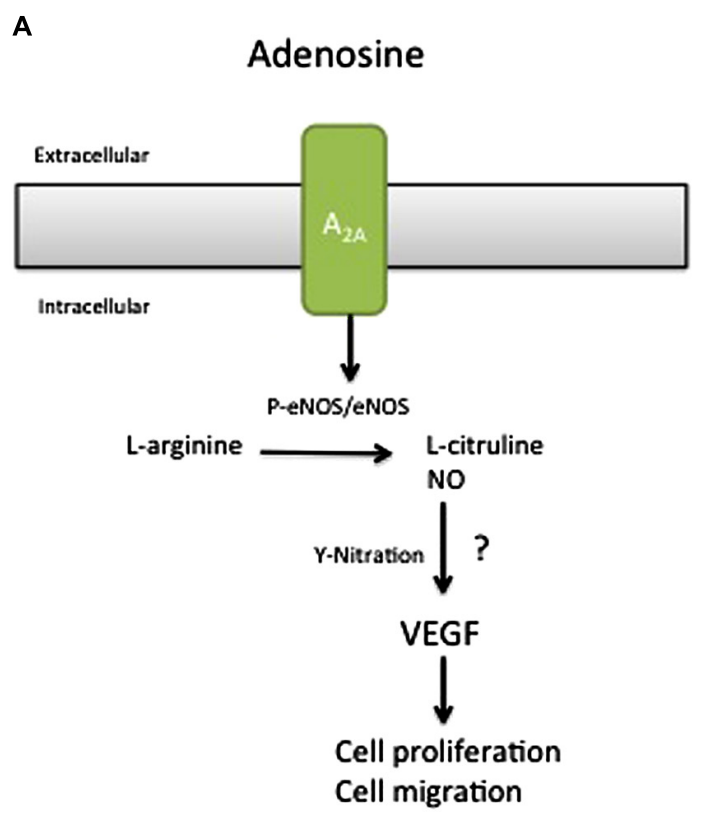

FIGURE 2 | Model of the effect of the $A_{2 A} A R / N O / V E G F$ signaling pathway in cell migration and proliferation during preeclampsia. Late-onset preeclampsia (A) is associated with elevated activation of $\mathrm{A}_{2 \mathrm{~A}}$ adenosine receptor, characterized by high $(\uparrow)$ eNOS activation, NO formation, and nitrotyrosine formation (Y-nitration), associated with enhancement of cell proliferation and migration. On the other hand, early-onset preeclampsia (B) is associated with a reduction $(\downarrow)$ in the
B

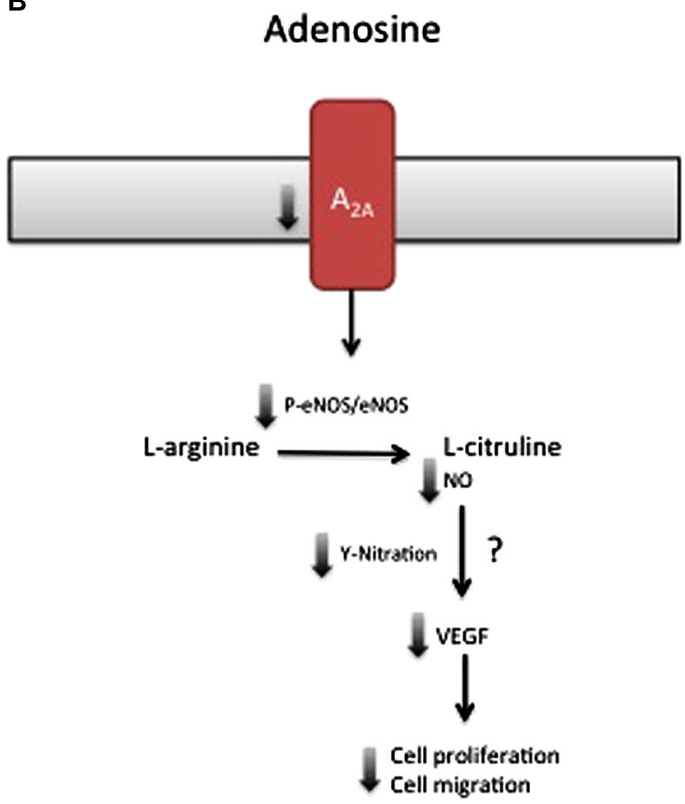

abundance of $A_{2 A}$ adenosine receptor, which in turn could be reduced with a decline in eNOS activation, NO formation, and Y-nitration and might explain the reduced HUVEC migration and proliferation observed in this disease. Despite this hypothesis, it is unclear (?) whether NO generated by $A_{2 A}$ stimulation can modulate the expression or activation of VEGF or activate other signaling pathways involved in cell migration and proliferation in early-onset preeclampsia. pro-angiogenic factors like VEGF (Kimura et al., 2002; Feoktistov et al., 2004). Considering that NO can cause nitration of tyrosine residues on HIF-1 $\alpha$ (Riano et al., 2011), and may contribute to stabilization, we propose that the reduced adenosine-mediated NO synthesis observed in EOPE might be associated with impaired HIF-dependent VEGF expression (see Figure 3). Clearly, more studies are necessary to understand all the processes involved in these alterations.

Another question that needs to be answered is whether impaired adenosine-mediated angiogenesis in the feto-placental circulation of preeclamptic pregnancies persists after birth. In this context, Coney and Marshall (2010) have demonstrated that prenatal hypoxia has long-lasting effects on vascular function in the skeletal muscle of adult male rats. In particular, in a group of adult males, they investigated how chronic systemic hypoxia in utero (CHU) affects the cardiovascular response evoked by acute, systemic hypoxia. One of the most intriguing results was the fact that the overall magnitude of vasodilator response evoked in muscle by acute systemic hypoxia is similar in CHU and normoxic rats, but the mechanisms underlying the response appear to be different. Thus, they conclude that, whereas in normoxia, vasodilatory response is associated with the activation of endothelial $A_{1} A R$ and NO-dependent effects, in CHU, participation of $A_{1} A R$ is limited, and vasodilatory response in the muscle is replaced by factors other than adenosine. Moreover, it has been reported that mice deficient in $\mathrm{A}_{2 \mathrm{~A}} \mathrm{AR}\left(\mathrm{KO}-\mathrm{A}_{2 \mathrm{~A}} \mathrm{AR}\right.$ ) exhibit no significant difference in systemic blood pressure compared to wild-type animals, but they do develop pulmonary artery hypertension and pulmonary vascular remodeling ( $\mathrm{Xu}$ et al., 2011). Thus, these studies demonstrate how the adenosine-impaired angiogenesis and vascular remodeling observed in pathological pregnancies such as preeclampsia may be related to future cardiovascular risk.

\section{CONCLUDING REMARKS AND FUTURE DIRECTIONS}

That fetuses exposed to preeclampsia are at increased risk to develop hypertension later in life has been associated with the occurrence of endothelial dysfunction. Since the endothelium is one of the main factors in the normal process of angiogenesis, an impaired endothelial/angiogenic response in offspring from preeclamptic pregnancies may constitute the underlying mechanism associated with hypertension. On the other hand, preeclampsia is associated with elevated levels of adenosine and low expression and response of $\mathrm{A}_{2 \mathrm{~A}} \mathrm{AR}$, but high expression of $\mathrm{A}_{2 \mathrm{~B}} \mathrm{AR}$, defects that might be involved in abnormal placental and newborn angiogenic processes. Then, adenosine may constitute a potential new target for improving placental angiogenesis. Furthermore, impairment of those mechanisms may contribute to susceptibility to cardiovascular diseases, including hypertension, in children exposed to preeclampsia.

As presented in this review, there are many questions that need to be answered regarding adenosine-mediated angiogenesis in preeclampsia. Therefore, future studies should consider at least the following inquires. Why $\mathrm{A}_{2 \mathrm{~A}} \mathrm{AR}$ expression is reduced in 


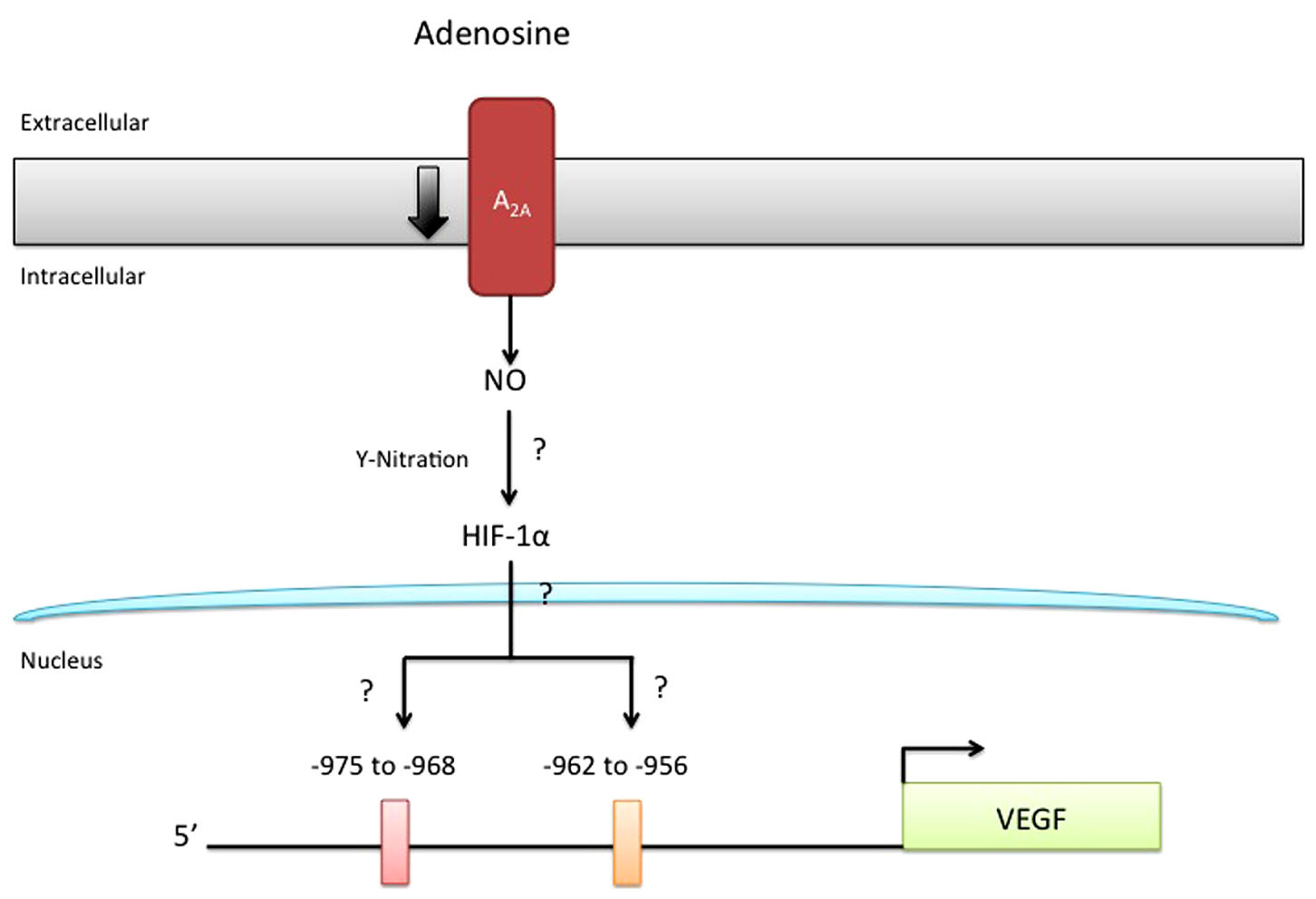

FIGURE 3 | Reduced $A_{2 A} A R / N O$ signaling pathway may involve HIF nitration. It has been hypothesized that nitration of hypoxia inducible factor (HIF) may control the expression of several genes, including vascular endothelial growth factor (VEGF). Since adenosine requires HIF for the induction of VEGF-promoter activity and because this receptor triggers an intracellular signaling involving protein nitration in normal and preeclamptic endothelial cells, it is unknown (?) whether HIF-nitration after $\mathrm{A}_{2 \mathrm{~A}} \mathrm{AR}$ stimulation might control HIF-binding to a specific site (including -975 to -968 ; and -962 to -956 ) in the VEGF promoter. preeclampsia? Future studies should consider analysis of translational and transcriptional regulation of $\mathrm{A}_{2 \mathrm{~A}} \mathrm{AR}$ expression in endothelial cells derived from preeclampsia. Also, it should be determined whether the reduction in total $\mathrm{A}_{2 \mathrm{~A}} \mathrm{AR}$ levels observed in preeclampsia, leads to a reduction in the cell surface expression and in the activation of this receptor. Studies are also needed to investigate how cross-talk between intracellular pathways related to adenosine receptor activation might change during preeclampsia; and how these phenomena might generate a compensatory response via other adenosine receptors including $\mathrm{A}_{2 \mathrm{~B}} \mathrm{AR}$. As highlighted in this review, it is also necessary to determine whether adenosine-mediated angiogenesis is present after birth in newborns and children exposed to preeclampsia. These studies are difficult to perform in humans due to ethical and technical issues; but certainly animal models might help. Mice deficient in each one of the adenosine receptors have been developed, providing an excellent model to address these last questions. We hope that this review will contribute to awareness, within the scientific community, of this important issue and stimulate further investigation in this area.

\section{ACKNOWLEDGMENTS}

The authors are grateful to the midwives and medical staff in the Obstetric and Gynecology Department of Hospital Clinico Herminda Martin in Chillan, Chile. They thank all research staff of the
Vascular Physiology Laboratory and the Group of Investigation of Tumor Angiogenesis (GIANT) of the Universidad del Bio Bio for their technical support. They also appreciate the technical support given by researchers in the Group of Research and Innovation in Vascular Health (GRIVAS Health) and the editorial help given by Mr. Bruce Campbell and Ms. Lee Rager from the Magee-Womens Research Institute. Fondecyt Regular 1100684, Conicyt 79112027, DIUBB 122109 GI/EF, National Heart, Lung, and Blood Institute R01HL095787, and National Cancer Institute R01CA138923 supported this work.

\section{REFERENCES}

ACOG, Task Force of Hypertension in Pregnancy. (2013). Hypertension in Pregnancy. Washington. American College of Obstetrician and Gynecologists.

Acurio, J., Troncoso, F., Bertoglia, P., Salomon, C., Aguayo, C., Sobrevia, L., et al. (2014). Potential role of A2B adenosine receptors on proliferation/migration of fetal endothelium derived from pre-eclamptic pregnancies. BioMed Res. Int. 2014:274507. doi: 10.1155/2014/274507

Afzal, A., Shaw, L. C., Caballero, S., Spoerri, P. E., Lewin, A. S., Zeng, D., etal. (2003). Reduction in preretinal neovascularization by ribozymes that cleave the A2B adenosine receptor mRNA. Circ. Res. 93, 500-506. doi: 10.1161/01.RES.0000091260.78959.BC

Ahmad, A., Ahmad, S., Glover, L., Miller, S. M., Shannon, J. M., Guo, X., et al. (2009). Adenosine A2A receptor is a unique angiogenic target of HIF-2alpha in pulmonary endothelial cells. Proc. Natl. Acad. Sci. U.S.A. 106, 10684-10689. doi: 10.1073/pnas.0901326106 
Andraweera, P. H., Dekker, G. A., Laurence, J. A., and Roberts, C. T. (2012). Placental expression of VEGF family mRNA in adverse pregnancy outcomes. Placenta 33, 467-472. doi: 10.1016/j.placenta.2012.02.013

Belfort, M. B., Gillman, M. W., and Mccormick, M. C. (2012). Prenatal and perinatal predictors of blood pressure at school age in former preterm, low birth weight infants. J. Perinatol. 32, 265-269. doi: 10.1038/jp.2011.88

Brown, S. T., Reyes, E. P., and Nurse, C. A. (2011). Chronic hypoxia upregulates adenosine $2 \mathrm{~A}$ receptor expression in chromaffin cells via hypoxia inducible factor2alpha: role in modulating secretion. Biochem. Biophys. Res. Commun. 412, 466472. doi: 10.1016/j.bbrc.2011.07.122

Brunner, H., Cockcroft, J. R., Deanfield, J., Donald, A., Ferrannini, E., Halcox, J., et al. (2005). Endothelial function and dysfunction. Part II: association with cardiovascular risk factors and diseases. A statement by the Working Group on Endothelins and Endothelial Factors of the European Society of Hypertension. J. Hypertens. 23, 233-246. doi: 10.1097/00004872-200502000-00001

Bshesh, K., Zhao, B., Spight, D., Biaggioni, I., Feokistov, I., Denenberg, A. et al. (2002). The A2A receptor mediates an endogenous regulatory pathway of cytokine expression in THP-1 cells. J. Leukoc. Biol. 72, 1027-1036.

Burton, G. J., Charnock-Jones, D. S., and Jauniaux, E. (2009a). Regulation of vascular growth and function in the human placenta. Reproduction 138, 895-902. doi: 10.1530/REP-09-0092

Burton, G. J., Woods, A. W., Jauniaux, E., and Kingdom, J. C. (2009b). Rheological and physiological consequences of conversion of the maternal spiral arteries for uteroplacental blood flow during human pregnancy. Placenta 30, 473-482. doi: 10.1016/j.placenta.2009.02.009

Byers, B. D., Betancourt, A., Lu, F., Hankins, G. D., Longo, M., Saade, G. R., et al. (2009). The effect of prepregnancy obesity and sFlt-1-induced preeclampsia-like syndrome on fetal programming of adult vascular function in a mouse model Am. J. Obstet. Gynecol. 200, 432.e431-e437. doi: 10.1016/j.ajog.2009.01.044

Bytautiene, E., Tamayo, E., Kechichian, T., Drever, N., Gamble, P., Hankins, G. D., et al. (2011). Prepregnancy obesity and sFlt1-induced preeclampsia in mice: developmental programming model of metabolic syndrome. Am. J. Obstet. Gynecol. 204, 398.e1-398.e8. doi: 10.1016/j.ajog.2011.02.031

Casanello, P., Escudero, C., and Sobrevia, L. (2007). Equilibrative nucleoside (ENTs) and cationic amino acid (CATs) transporters: implications in foetal endothelia dysfunction in human pregnancy diseases. Curr. Vasc. Pharmacol. 5, 69-84. doi: 10.2174/157016107779317198

Chen, X., and Wang, Y. (2008). Tracking of blood pressure from childhood to adulthood: a systematic review and meta-regression analysis. Circulation 117, 3171-3180. doi: 10.1161/CIRCULATIONAHA.107.730366

Cheng, S. W., Chou, H. C., Tsou, K. I., Fang, L. J., and Tsao, P. N. (2004). Delivery before 32 weeks of gestation for maternal pre-eclampsia: neonatal outcome and 2-year developmental outcome. Early Hum. Dev. 76, 39-46. doi: 10.1016/j.earlhumdev.2003.10.004

Clark, A. N., Youkey, R., Liu, X., Jia, L., Blatt, R., Day, Y. J., et al. (2007). Al adenosine receptor activation promotes angiogenesis and release of VEGF from monocytes. Circ. Res. 101, 1130-1138. doi: 10.1161/CIRCRESAHA.107.150110

Coney, A. M., and Marshall, J. M. (2010). Effects of maternal hypoxia on muscle vasodilatation evoked by acute systemic hypoxia in adult rat offspring: changed roles of adenosine and Al receptors. J. Physiol. 588, 5115-5125. doi: 10.1113/jphysiol.2010.198275

Davis, E. F., Lazdam, M., Lewandowski, A. J., Worton, S. A., Kelly, B., Kenworthy, Y., et al. (2012a). Cardiovascular risk factors in children and young adults born to preeclamptic pregnancies: a systematic review. Pediatrics 129, e1552-e1561. doi: 10.1542/peds.2011-3093

Davis, E. F., Newton, L., Lewandowski, A. J., Lazdam, M., Kelly, B. A., Kyriakou, T., etal. (2012b). Pre-eclampsia and offspring cardiovascular health: mechanistic insights from experimental studies. Clin. Sci. 123, 53-72. doi: 10.1042/CS20110627

Desai, A., Victor-Vega, C., Gadangi, S., Montesinos, M. C., Chu, C. C., and Cronstein, B. N. (2005). Adenosine A2A receptor stimulation increases angiogenesis by down-regulating production of the antiangiogenic matrix protein thrombospondin 1. Mol. Pharmacol. 67, 1406-1413. doi: 10.1124/mol.104.007807

Dubey, R. K., Gillespie, D. G., and Jackson, E. K. (2002). A(2B) adenosine receptors stimulate growth of porcine and rat arterial endothelial cells. Hypertension 39, 530-535. doi: 10.1161/hy0202.103075

Duley, L. (2009). The global impact of pre-eclampsia and eclampsia. Semin. Perinatol. 33, 130-137. doi: 10.1053/j.semperi.2009.02.010
Dye, J., Lawrence, L., Linge, C., Leach, L., Firth, J., and Clark, P. (2004) Distinct patterns of microvascular endothelial cell morphology are determined by extracellular matrix composition. Endothelium 11, 151-167. doi: 10.1080/10623320490512093

Eckle, T., Krahn, T., Grenz, A., Kohler, D., Mittelbronn, M., Ledent, C., et al. (2007). Cardioprotection by ecto- $5^{\prime}$-nucleotidase (CD73) and A2B adenosine receptors. Circulation 115, 1581-1590. doi: 10.1161/CIRCULATIONAHA.106.669697

Eltzschig, H. K., Ibla, J. C., Furuta, G. T., Leonard, M. O., Jacobson, K. A., Enjyoji, K., et al. (2003). Coordinated adenine nucleotide phosphohydrolysis and nucleoside signaling in posthypoxic endothelium: role of ectonucleotidases and adenosine A2B receptors. J. Exp. Med. 198, 783-796. doi: 10.1084/jem.20030891

Ernens, I., Leonard, F., Vausort, M., Rolland-Turner, M., Devaux, Y., and Wagner, D. R. (2010). Adenosine up-regulates vascular endothelial growth factor in human macrophages. Biochem. Biophys. Res. Commun. 392, 351-356. doi: 10.1016/j.bbrc.2010.01.023

Escudero, C., Bertoglia, P., Hernadez, M., Celis, C., Gonzalez, M., Aguayo, C., et al. (2012). Impaired A(2A) adenosine receptor/nitric oxide/VEGF signaling pathway in fetal endothelium during late- and early-onset preeclampsia. Purinergic Signal. doi: 10.1007/s11302-012-9341-4

Escudero, C., Casanello, P., and Sobrevia, L. (2008). Human equilibrative nucleoside transporters 1 and 2 may be differentially modulated by A2B adenosine receptors in placenta microvascular endothelial cells from pre-eclampsia. Placenta 29, 816825. doi: 10.1016/j.placenta.2008.06.014

Escudero, C., Celis, C., Saez, T., San Martin, S., Valenzuela, F. J., Aguayo, C., et al. (2014). Increased placental angiogenesis in late and early onset pre-eclampsia is associated with differential activation of vascular endothelial growth factor receptor 2. Placenta 35, 207-215. doi: 10.1016/j.placenta.2014.01.007

Escudero, C., Puebla, C., Westermeier, F., and Sobrevia, L. (2009). Potential cell signalling mechanisms involved in differential placental angiogenesis in mild and severe pre-eclampsia. Curr. Vasc. Pharmacol. 7, 475-485. doi: $10.2174 / 157016109789043865$

Escudero, C., and Sobrevia, L. (2008). A hypothesis for preeclampsia: adenosine and inducible nitric oxide synthase in human placental microvascular endothelium. Placenta 29, 469-483. doi: 10.1016/j.placenta.2008.02.008

Escudero, C., and Sobrevia, L. (2009). "Understanding physiological significance of high extracellular adenosine levels in feto-placental circulation in preeclamptic pregnancies," in Membrane Transporters and Receptors in Disease, eds L. Sobrevia and P. Casanello (Kerala, India: Research Signpost), 27-51.

Escudero, C., and Sobrevia, L. (2012). Adenosine plasma levels in the fetoplacental circulation in preeclampsia. Am. J. Obstet. Gynecol. 206, e5-e6. doi: 10.1016/j.ajog.2011.12.032

Espinoza, J., Espinoza, A. F., and Power, G. G. (2011). High fetal plasma adenosine concentration: a role for the fetus in preeclampsia? Am. J. Obstet. Gynecol. 205, 485.e24-485.e27. doi: 10.1016/j.ajog.2011.06.034

Fang, Y., and Olah, M. E. (2007). Cyclic AMP-dependent, protein kinase A-independent activation of extracellular signal-regulated kinase $1 / 2$ following adenosine receptor stimulation in human umbilical vein endothelial cells: role of exchange protein activated by cAMP 1 (Epac1). J. Pharmacol. Exp. Ther. 322, 1189-1200. doi: 10.1124/jpet.107.119933

Feoktistov, I., and Biaggioni, I. (1995). Adenosine A2b receptors evoke interleukin8 secretion in human mast cells. An enprofylline-sensitive mechanism with implications for asthma. J. Clin. Invest. 96, 1979-1986. doi: 10.1172/JCI118245

Feoktistov, I., Goldstein, A. E., Ryzhov, S., Zeng, D., Belardinelli, L., VoynoYasenetskaya, T., et al. (2002). Differential expression of adenosine receptors in human endothelial cells: role of $\mathrm{A} 2 \mathrm{~B}$ receptors in angiogenic factor regulation. Circ. Res. 90, 531-538. doi: 10.1161/01.RES.0000012203.21416.14

Feoktistov, I., Ryzhov, S., Goldstein, A. E., and Biaggioni, I. (2003). Mast cell-mediated stimulation of angiogenesis: cooperative interaction between A2B and A3 adenosine receptors. Circ. Res. 92, 485-492. doi: 10.1161/01.RES.0000061572.10929.2D

Feoktistov, I., Ryzhov, S., Zhong, H., Goldstein, A. E., Matafonov, A., Zeng, D., et al. (2004). Hypoxia modulates adenosine receptors in human endothelial and smooth muscle cells toward an A2B angiogenic phenotype. Hypertension 44, 649-654. doi: 10.1161/01.HYP.0000144800.21037.a5

Gellhaus, A., Schmidt, M., Dunk, C., Lye, S. J., Kimmig, R., and Winterhager, E. (2006). Decreased expression of the angiogenic regulators CYR61 (CCN1) and NOV (CCN3) in human placenta is associated with pre-eclampsia. Mol. Hum. Reprod. 12, 389-399. doi: 10.1093/molehr/gal044 
George, E. M., Cockrell, K., Adair, T. H., and Granger, J. P. (2010). Regulation of sFlt-1 and VEGF secretion by adenosine under hypoxic conditions in rat placental villous explants. Am. J. Physiol. Regul. Integr. Comp. Physiol. 299, R1629-R1633. doi: 10.1152/ajpregu.00330.2010

Gessi, S., Fogli, E., Sacchetto, V., Merighi, S., Varani, K., Preti, D., et al. (2010) Adenosine modulates HIF-1 $\{$ alpha\}, VEGF, IL-8, and foam cell formation in a human model of hypoxic foam cells. Arterioscler. Thromb. Vasc. Biol. 30, 90-97. doi: 10.1161/ATVBAHA.109.194902

Glover, V. (2011). Annual research review: prenatal stress and the origins of psychopathology: an evolutionary perspective. J. Child Psychol. Psychiatry 52, 356-367. doi: 10.1111/j.1469-7610.2011.02371.x

Gluckman, P. D., and Hanson, M. A. (2004). Living with the past: evolution, development, and patterns of disease. Science 305, 1733-1736. doi: 10.1126/science. 1095292

Grant, M. B., Davis, M. I., Caballero, S., Feoktistov, I., Biaggioni, I., and Belardinelli, L. (2001). Proliferation, migration, and ERK activation in human retinal endothelial cells through A(2B) adenosine receptor stimulation. Invest. Ophthalmol. Vis. Sci. 42, 2068-2073.

Grant, M. B., Tarnuzzer, R. W., Caballero, S., Ozeck, M. J., Davis, M. I., Spoerri, P. E., et al. (1999). Adenosine receptor activation induces vascular endothelial growth factor in human retinal endothelial cells. Circ. Res. 85, 699-706. doi: 10.1161/01.RES.85.8.699

Greene, J. M., Dunaway, C. W., Bowers, S. D., Rude, B. J., Feugang, J. M., and Ryan, P. L. (2011). In vivo monitoring of fetoplacental Vegfr2 gene activity in a murine pregnancy model using a Vegfr2-luc reporter gene and bioluminescent imaging. Reprod. Biol. Endocrinol. 51. doi: 10.1186/1477-7827-9-51

Griffith, M. I., Mann, J. R., and Mcdermott, S. (2011). The risk of intellectua disability in children born to mothers with preeclampsia or eclampsia with partial mediation by low birth weight. Hypertens. Pregnancy 30, 108-115. doi: 10.3109/10641955.2010.507837

Hanson, M. A., and Gluckman, P. D. (2008). Developmental origins of health and disease: new insights. Basic Clin. Pharmacol. Toxicol. 102, 90-93. doi: 10.1111/j.1742-7843.2007.00186.x

Harb, R., Whiteus, C., Freitas, C., and Grutzendler, J. (2013). In vivo imaging of cerebral microvascular plasticity from birth to death. J. Cereb. Blood Flow Metab. 33, 146-156. doi: 10.1038/jcbfm.2012.152

Headrick, J. P., Ashton, K. J., Rose'meyer, R. B., and Peart, J. N. (2013). Cardiovascular adenosine receptors: expression, actions and interactions. Pharmacol. Ther. doi: 10.1016/j.pharmthera.2013.06.002

Hiller, J. E., Crowther, C. A., Moore, V. A., Willson, K., and Robinson, J. S. (2007). Calcium supplementation in pregnancy and its impact on blood pressure in children and women: follow up of a randomised controlled trial. Aust. N. Z. J. Obstet. Gynaecol. 47, 115-121. doi: 10.1111/j.1479-828X.2007. 00696.x

Jacobson, K. A., and Gao, Z. G. (2006). Adenosine receptors as therapeutic targets. Nat. Rev. Drug Discov. 5, 247-264. doi: 10.1038/nrd1983

Jayet, P. Y., Rimoldi, S. F., Stuber, T., Salmon, C. S., Hutter, D., Rexhaj, E., et al. (2010). Pulmonary and systemic vascular dysfunction in young offspring of mothers with preeclampsia. Circulation 122, 488-494. doi: 10.1161/CIRCULATIONAHA.110.941203

Junus, K., Centlow, M., Wikstrom, A. K., Larsson, I., Hansson, S. R., and Olovsson, M. (2012). Gene expression profiling of placentae from women with earlyand late-onset pre-eclampsia: down-regulation of the angiogenesis-related genes ACVRL1 and EGFL7 in early-onset disease. Mol. Hum. Reprod. 18, 146-155. doi: 10.1093/molehr/gar067

Kafkasli, A., Karabulut, A. B., Atmaca, R., and Laurini, R. (2006). Clinical correlation between adenosine deaminase activity and pre-eclampsia severity. J. Int. Med. Res. 34, 247-255. doi: 10.1177/147323000603400303

Kajantie, E., Eriksson, J. G., Osmond, C., Thornburg, K., and Barker, D. J. (2009). Pre-eclampsia is associated with increased risk of stroke in the adult offspring: the Helsinki birth cohort study. Stroke 40, 1176-1180. doi: 10.1161/STROKEAHA.108.538025

Kim, G. D., Oh, J., Jeong, L. S., and Lee, S. K. (2013). Thio-Cl-IB-MECA, a novel A(3) adenosine receptor agonist, suppresses angiogenesis by regulating $\mathrm{PI} 3 \mathrm{~K} / \mathrm{AKT} / \mathrm{mTOR}$ and ERK signaling in endothelial cells. Biochem. Biophys. Res. Commun. 437, 79-86. doi: 10.1016/j.bbrc.2013.06.040

Kim, S. C., Park, M. J., Joo, B. S., Joo, J. K., Suh, D. S., and Lee, K. S. (2012). Decreased expressions of vascular endothelial growth factor and visfatin in the placental bed of pregnancies complicated by preeclampsia. J. Obstet. Gynaecol. Res. 38, 665-673. doi: 10.1111/j.1447-0756.2011.01773.X

Kim, Y. H., Hwang, H. S., Kim, Y. T., Kim, H. S., and Park, Y. W. (2008). Modulation of matrix metalloproteinase secretion by adenosine A3 receptor in preeclamptic villous explants. Reprod. Sci. 15, 939-949. doi: 10.1177/1933719108322431

Kimura, H., Ogura, T., Kurashima, Y., Weisz, A., and Esumi, H. (2002). Effects of nitric oxide donors on vascular endothelial growth factor gene induction. Biochem. Biophys. Res. Commun. 296, 976-982. doi: 10.1016/S0006291X(02)02029-6

Kimura, H., Weisz, A., Kurashima, Y., Hashimoto, K., Ogura, T., D’acquisto, F., et al. (2000). Hypoxia response element of the human vascular endothelial growth factor gene mediates transcriptional regulation by nitric oxide: control of hypoxia-inducible factor-1 activity by nitric oxide. Blood 95, 189-197.

Kong, T., Westerman, K. A., Faigle, M., Eltzschig, H. K., and Colgan, S. P. (2006). HIF-dependent induction of adenosine A2B receptor in hypoxia. FASEB J. 20, 2242-2250. doi: 10.1096/fj.06-6419com

Krause, B., Sobrevia, L., and Casanello, P. (2009). Epigenetics: new concepts of old phenomena in vascular physiology. Curr. Vasc. Pharmacol. 7, 513-520. doi: 10.2174/157016109789043883

Kvehaugen, A. S., Andersen, L. F., and Staff, A. C. (2010). Anthropometry and cardiovascular risk factors in women and offspring after pregnancies complicated by preeclampsia or diabetes mellitus. Acta Obstet. Gynecol. Scand. 89, 1478-1485. doi: $10.3109 / 00016349.2010 .500368$

Kvehaugen, A. S., Dechend, R., Ramstad, H. B., Troisi, R., Fugelseth, D., and Staff, A. C. (2011). Endothelial function and circulating biomarkers are disturbed in women and children after preeclampsia. Hypertension 58, 63-69. doi: 10.1161/HYPERTENSIONAHA.111.172387

Kwon, J. Y., Maeng, Y. S., Kwon, Y. G., Kim, Y. H., Kang, M. H., and Park, Y. W. (2007). Decreased endothelial progenitor cells in umbilical cord blood in severe preeclampsia. Gynecol. Obstet. Invest. 64, 103-108. doi: 10.1159/000100081

Lankhorst, S., Kappers, M. H., Van Esch, J. H., Danser, A. H., and Van Den Meiracker, A. H. (2013). Hypertension during vascular endothelial growth factor inhibition: focus on nitric oxide, endothelin-1, and oxidative stress. Antioxid. Redox Signal. doi: 10.1089 /ars.2013.5244

Lawlor, D. A., Macdonald-Wallis, C., Fraser, A., Nelson, S. M., Hingorani, A., Davey Smith, G., et al. (2012). Cardiovascular biomarkers and vascular function during childhood in the offspring of mothers with hypertensive disorders of pregnancy: findings from the Avon Longitudinal Study of Parents and Children. Eur. Heart J. 33, 335-345. doi: 10.1093/eurheartj/ehr300

Lazdam, M., De La Horra, A., Pitcher, A., Mannie, Z., Diesch, J., Trevitt, C., et al. (2010). Elevated blood pressure in offspring born premature to hypertensive pregnancy: is endothelial dysfunction the underlying vascular mechanism? Hypertension 56, 159-165. doi: 10.1161/HYPERTENSIONAHA.110.150235

Lee, S. J., Hwang, H. S., Kim, B. N., Kim, M. A., Lee, J. W., Park, Y. W., et al. (2007). Changes in serum adenosine deaminase activity during normal pregnancy. J. Korean Med. Sci. 22, 718-721. doi: 10.3346/jkms.2007.22.4.718

Leibovich, S. J., Chen, J. F., Pinhal-Enfield, G., Belem, P. C., Elson, G., Rosania, A., et al. (2002). Synergistic up-regulation of vascular endothelial growth factor expression in murine macrophages by adenosine $\mathrm{A}(2 \mathrm{~A})$ receptor agonists and endotoxin. Am. J. Pathol. 160, 2231-2244. doi: 10.1016/S0002-9440(10)61170-4

Lennon, P. F., Taylor, C. T., Stahl, G. L., and Colgan, S. P. (1998). Neutrophil-derived 5 '-adenosine monophosphate promotes endothelial barrier function via CD73mediated conversion to adenosine and endothelial A2B receptor activation. J. Exp. Med. 188, 1433-1443. doi: 10.1084/jem.188.8.1433

Leonard, F., Devaux, Y., Vausort, M., Ernens, I., Rolland-Turner, M., and Wagner, D. R. (2011). Adenosine modifies the balance between membrane and soluble forms of Flt-1. J. Leukoc. Biol. 90, 199-204. doi: 10.1189/jlb.0910505

Letourneur, A., Freret, T., Roussel, S., Boulouard, M., Divoux, D., Toutain, J., et al. (2012). Maternal hypertension during pregnancy modifies the response of the immature brain to hypoxia-ischemia: sequential MRI and behavioral investigations. Exp. Neurol. 233, 264-272. doi: 10.1016/j.expneurol.2011. 10.014

Li, J., Fenton, R. A., Wheeler, H. B., Powell, C. C., Peyton, B. D., Cutler, B. S., et al. (1998). Adenosine A2a receptors increase arterial endothelial cell nitric oxide. J. Surg. Res. 80, 357-364. doi: 10.1006/jsre.1998.5439

Loffler, M., Morote-Garcia, J. C., Eltzschig, S. A., Coe, I. R., and Eltzschig, H. K. (2007). Physiological roles of vascular nucleoside transporters. Arterioscler. Thromb. Vasc. Biol. 27, 1004-1013. doi: 10.1161/ATVBAHA.106.126714 
Lu, F., Bytautiene, E., Tamayo, E., Gamble, P., Anderson, G. D., Hankins, G. D., et al. (2007a). Gender-specific effect of overexpression of sFlt-1 in pregnant mice on fetal programming of blood pressure in the offspring later in life. Am. J. Obstet. Gynecol. 197, 418.el-e418.e5. doi: 10.1016/j.ajog.2007.06.064

Lu, F., Longo, M., Tamayo, E., Maner, W., Al-Hendy, A., Anderson, G. D., et al. (2007b). The effect of over-expression of sFlt-1 on blood pressure and the occurrence of other manifestations of preeclampsia in unrestrained conscious pregnant mice. Am. J. Obstet. Gynecol. 196, 396.e1-396.e7; discussion 396.e397. doi: 10.1016/j.ajog.2006.12.024

Lyall, F., Young, A., Boswell, F., Kingdom, J. C., and Greer, I. A. (1997). Placental expression of vascular endothelial growth factor in placentae from pregnancies complicated by pre-eclampsia and intrauterine growth restriction does not support placental hypoxia at delivery. Placenta 18, 269-276. doi: 10.1016/S0143-4004(97)80061-6

MacLauchlan, S., Yu, J., Parrish, M., Asoulin, T. A., Schleicher, M., Krady, M. M., et al. (2011). Endothelial nitric oxide synthase controls the expression of the angiogenesis inhibitor thrombospondin 2. Proc. Natl. Acad. Sci. U.S.A. 108 E1137-E1145. doi: 10.1073/pnas.1104357108

Maynard, S. E., Min, J. Y., Merchan, J., Lim, K. H., Li, J., Mondal, S., et al. (2003) Excess placental soluble fms-like tyrosine kinase 1 (sFlt1) may contribute to endothelial dysfunction, hypertension, and proteinuria in preeclampsia. J. Clin. Invest. 111, 649-658. doi: 10.1172/JCI17189

Merighi, S., Benini, A., Mirandola, P., Gessi, S., Varani, K., Simioni, C., et al (2007). Caffeine inhibits adenosine-induced accumulation of hypoxia-inducible factor-lalpha, vascular endothelial growth factor, and interleukin-8 expression in hypoxic human colon cancer cells. Mol. Pharmacol. 72, 395-406. doi: $10.1124 / \mathrm{mol} .106 .032920$

Merighi, S., Simioni, C., Gessi, S., Varani, K., Mirandola, P., Tabrizi, M. A. et al. (2009). A(2B) and A(3) adenosine receptors modulate vascular endothelial growth factor and interleukin-8 expression in human melanoma cells treated with etoposide and doxorubicin. Neoplasia 11, 1064-1073.

Monga, R., Buck, S., Sharma, P., Thomas, R., and Chouthai, N. S. (2012). Effect of preeclampsia and intrauterine growth restriction on endothelial progenitor cells in human umbilical cord blood. J. Matern Fetal Neonatal. Med. 25, 2385-2389. doi: 10.3109/14767058.2012.697228

Murfee, W. L., and Schmid-Schonbein, G. W. (2008). Chapter 12. Structure of microvascular networks in genetic hypertension. Methods Enzymol. 444, 271-284 doi: 10.1016/S0076-6879(08)02812-7

Murphy, S. R., Lamarca, B., Cockrell, K., Arany, M., and Granger, J. P. (2012). L-Arginine supplementation abolishes the blood pressure and endothelin response to chronic increases in plasma sFlt-1 in pregnant rats. Am. J. Physiol. Regul. Integr. Comp. Physiol. 302, R259-R263. doi: 10.1152/ajpregu. 00319.2011

Noon, J. P., Walker, B. R., Webb, D. J., Shore, A. C., Holton, D. W., Edwards, H. V., et al. (1997). Impaired microvascular dilatation and capillary rarefaction in young adults with a predisposition to high blood pressure. J. Clin. Invest. 99 1873-1879. doi: 10.1172/JCI119354

Oglaend, B., Forman, M. R., Romundstad, P. R., Nilsen, S. T., and Vatten, L. J. (2009). Blood pressure in early adolescence in the offspring of preeclamptic and normotensive pregnancies. J. Hypertens. 27, 2051-2054. doi: 10.1097/HJH.0b013e328330052a

Olah, M. E., and Stiles, G. L. (2000). The role of receptor structure in determining adenosine receptor activity. Pharmacol. Ther. 85, 55-75. doi: 10.1016/S0163 7258(99)00051-0

Ounsted, M., Cockburn, J., Moar, V. A., and Redman, C. W. (1983). Materna hypertension with superimposed pre-eclampsia: effects on child development at 71/2 years. Br. J. Obstet. Gynaecol. 90, 644-649. doi: 10.1111/j.14710528.1983.tb09283.x

Palmsten, K., Buka, S. L., and Michels, K. B. (2010). Maternal pregnancy-related hypertension and risk for hypertension in offspring later in life. Obstet. Gynecol. 116, 858-864. doi: 10.1097/AOG.0b013e3181f3alf9

Palti, H., and Rothschild, E. (1989). Blood pressure and growth at 6 years of age among offsprings of mothers with hypertension of pregnancy. Early Hum. Dev. 19, 263-269. doi: 10.1016/0378-3782(89)90061-3

Pinhal-Enfield, G., Ramanathan, M., Hasko, G., Vogel, S. N., Salzman, A. L., Boons, G. J., etal. (2003). An angiogenic switch in macrophages involving synergy between Toll-like receptors 2, 4, 7, and 9 and adenosine A(2A) receptors. Am. J. Pathol. 163, 711-721. doi: 10.1016/S0002-9440(10)63698-X
Pladys, P., Sennlaub, F., Brault, S., Checchin, D., Lahaie, I., Le, N. L., et al. (2005). Microvascular rarefaction and decreased angiogenesis in rats with fetal programming of hypertension associated with exposure to a low-protein diet in utero. Am. J. Physiol. Regul. Integr. Comp. Physiol. 289, R1580-R1588. doi: 10.1152/ajpregu.00031.2005

Riano, A., Ortiz-Masia, D., Velazquez, M., Calatayud, S., Esplugues, J. V., and Barrachina, M. D. (2011). Nitric oxide induces HIF-1alpha stabilization and expression of intestinal trefoil factor in the damaged rat jejunum and modulates ulcer healing. J. Gastroenterol. 46, 565-576. doi: 10.1007/s00535-011-0374-1

Risau, W. (1997). Mechanisms of angiogenesis. Nature 386, 671-674. doi: $10.1038 / 386671 \mathrm{a} 0$

Roberts, J. M., and Escudero, C. (2012). The placenta in preeclampsia. Hypertens. Pregnancy 2, 72-83. doi: 10.1016/j.preghy.2012.01.001

Roberts, J. M., Taylor, R. N., Musci, T. J., Rodgers, G. M., Hubel, C. A., and Mclaughlin, M. K. (1989). Preeclampsia: an endothelial cell disorder. Am. J. Obstet. Gynecol. 161, 1200-1204. doi: 10.1016/0002-9378(89)90665-0

Rolland-Turner, M., Goretti, E., Bousquenaud, M., Leonard, F., Nicolas, C., Zhang, L., et al. (2013). Adenosine stimulates the migration of human endothelial progenitor cells. Role of CXCR4 and microRNA-150. PLOS ONE 8:e54135. doi: 10.1371/journal.pone.0054135

Ryzhov, S., Biktasova, A., Goldstein, A. E., Zhang, Q., Biaggioni, I., Dikov, M. M., et al. (2014). Role of JunB in adenosine A2B receptor-mediated vascular endothelial growth factor production. Mol. Pharmacol. 85, 62-73. doi: 10.1124/mol.113.088567

Ryzhov, S., Solenkova, N. V., Goldstein, A. E., Lamparter, M., Fleenor, T., Young, P. P., et al. (2008). Adenosine receptor-mediated adhesion of endothelial progenitors to cardiac microvascular endothelial cells. Circ. Res. 102, 356-363. doi: 10.1161/CIRCRESAHA.107.158147

Saitoh, O., Saitoh, Y., and Nakata, H. (1994). Regulation of A2a adenosine receptor mRNA expression by agonists and forskolin in PC12 cells. Neuroreport 5, 13171320. doi: 10.1097/00001756-199406270-00005

Schaddelee, M. P., Voorwinden, H. L., Van Tilburg, E. W., Pateman, T. J., Ijzerman, A. P., Danhof, M., et al. (2003). Functional role of adenosine receptor subtypes in the regulation of blood-brain barrier permeability: possible implications for the design of synthetic adenosine derivatives. Eur. J. Pharm. Sci. 19, 13-22. doi: 10.1016/S0928-0987(03)00034-4

Schieke, S. M., Briviba, K., Klotz, L. O., and Sies, H. (1999). Activation pattern of mitogen-activated protein kinases elicited by peroxynitrite: attenuation by selenite supplementation. FEBS Lett. 448, 301-303. doi: 10.1016/S0014-5793(99)00372-5

Seidman, D. S., Laor, A., Gale, R., Stevenson, D. K., Mashiach, S., and Danon, Y. L. (1991). Pre-eclampsia and offspring's blood pressure, cognitive ability and physical development at 17-years-of-age. Br. J. Obstet. Gynaecol. 98, 1009-1014. doi: 10.1111/j.1471-0528.1991.tb15339.x

Shibuya, M. (2006). Differential roles of vascular endothelial growth factor receptor1 and receptor-2 in angiogenesis. J. Biochem. Mol. Biol. 39, 469-478. doi: 10.5483/BMBRep.2006.39.5.469

Shibuya, M. (2013). Vascular endothelial growth factor and its receptor system: physiological functions in angiogenesis and pathological roles in various diseases. J. Biochem. 153, 13-19. doi: 10.1093/jb/mvs136

Sibai, B., Dekker, G., and Kupferminc, M. (2005). Pre-eclampsia. Lancet 365, 785799. doi: 10.1016/S0140-6736(05)17987-2

Sobrevia, L., Guzmán-Gutiérrez, E., Westermeier, F., Salomón, C., Arroyo, P., Palacios, E., et al. (2012). "Fetoplacental vascular pathophysiology in preeclampsia," in Recent Research Developments in Physiology, ed. L. Sobrevia (India: Research Signpost), 105-158.

Sobrevia, L., Nadal, A., Yudilevich, D. L., and Mann, G. E. (1996). Activation of L-arginine transport (system $\mathrm{y}+$ ) and nitric oxide synthase by elevated glucose and insulin in human endothelial cells. J. Physiol. 490(Pt 3), 775-781.

Spaans, F., Vos, P. D., Bakker, W. W., Van Goor, H., and Faas, M. M. (2014). Danger signals from ATP and adenosine in pregnancy and preeclampsia. Hypertension 63, 1154-1160. doi: 10.1161/HYPERTENSIONAHA.114.03240

St. Hilaire, C., Carroll, S. H., Chen, H., and Ravid, K. (2009). Mechanisms of induction of adenosine receptor genes and its functional significance. J. Cell Physiol. 218, 35-44. doi: 10.1002/jcp.21579

Staff, A. C., Braekke, K., Harsem, N. K., Lyberg, T., and Holthe, M. R. (2005) Circulating concentrations of sFlt1 (soluble fms-like tyrosine kinase 1) in fetal and maternal serum during pre-eclampsia. Eur. J. Obstet. Gynecol. Reprod. Biol. 122, 33-39. doi: 10.1016/j.ejogrb.2004.11.015 
Staff, A. C., Braekke, K., Johnsen, G. M., Karumanchi, S. A., and Harsem, N. K. (2007). Circulating concentrations of soluble endoglin (CD105) in fetal and maternal serum and in amniotic fluid in preeclampsia. Am. J. Obstet. Gynecol. 197, 176.e1-176.e6. doi: 10.1016/j.ajog.2007.03.036

Stark, M. J., Clifton, V. L., and Wright, I. M. (2009). Neonates born to mothers with preeclampsia exhibit sex-specific alterations in microvascular function. Pediatr Res. 65, 292-295. doi: 10.1203/PDR.0b013e318193edf1

Swarup, J., Balkundi, D., Sobchak Brozanski, B., Roberts, J. M., and Yanowitz, T. D. (2005). Effect of preeclampsia on blood pressure in newborn very low birth weight infants. Hypertens. Pregnancy 24, 223-234. doi: 10.1080/1064195 0500281209

Szymonowicz, W., and Yu, V. Y. (1987). Severe pre-eclampsia and infants of very low birth weight. Arch. Dis. Child. 62, 712-716. doi: 10.1136/adc. 62.7.712

Takagi, H., King, G. L., Robinson, G. S., Ferrara, N., and Aiello, L. P. (1996). Adenosine mediates hypoxic induction of vascular endothelial growth factor in retinal pericytes and endothelial cells. Invest. Ophthalmol. Vis. Sci. 37, 2165-2176.

Tannetta, D. S., Dragovic, R. A., Gardiner, C., Redman, C. W., and Sargent, I L. (2013). Characterisation of syncytiotrophoblast vesicles in normal pregnancy and pre-eclampsia: expression of flt-1 and endoglin. PLoS ONE 8:e56754. doi: 10.1371/journal.pone.0056754

Tenhola, S., Rahiala, E., Halonen, P., Vanninen, E., and Voutilainen, R. (2006) Maternal preeclampsia predicts elevated blood pressure in 12-year-old children evaluation by ambulatory blood pressure monitoring. Pediatr. Res. 59, 320-324 doi: 10.1203/01.pdr.0000196734.54473.e3

Tenhola, S., Rahiala, E., Martikainen, A., Halonen, P., and Voutilainen, R. (2003) Blood pressure, serum lipids, fasting insulin, and adrenal hormones in 12-yearold children born with maternal preeclampsia. J. Clin. Endocrinol. Metab. 88, 1217-1222. doi: 10.1210/jc.2002-020903

Thadhani, R., Kisner, T., Hagmann, H., Bossung, V., Noack, S., Schaarschmidt, W., et al. (2011). Pilot study of extracorporeal removal of soluble fms-like tyrosine kinase 1 in preeclampsia. Circulation 124, 940-950. doi: 10.1161/CIRCULATIONAHA.111.034793

Tsao, P. N., Wei, S. C., Su, Y. N., Chou, H. C., Chen, C. Y., and Hsieh, W. S. (2005). Excess soluble fms-like tyrosine kinase 1 and low platelet counts in premature neonates of preeclamptic mothers. Pediatrics 116, 468-472. doi: 10.1542/peds.2004-2240

Tuovinen, S., Raikkonen, K., Kajantie, E., Pesonen, A. K., Heinonen, K., Osmond, C., et al. (2010). Depressive symptoms in adulthood and intrauterine exposure to pre-eclampsia: the Helsinki Birth Cohort Study. BJOG 117, 1236-1242. doi: 10.1111/j.1471-0528.2010.02634.x

Tuovinen, S., Raikkonen, K., Pesonen, A. K., Lahti, M., Heinonen, K., Wahlbeck, K., etal. (2012). Hypertensive disorders in pregnancy and risk of severe mental disorders in the offspring in adulthood: the Helsinki Birth Cohort Study. J. Psychiatr. Res. 46, 303-310. doi: 10.1016/j.jpsychires.2011. 11.015

Vatten, L. J., Romundstad, P. R., Holmen, T. L., Hsieh, C. C., Trichopoulos, D., and Stuver, S. O. (2003). Intrauterine exposure to preeclampsia and adolescent blood pressure, body size, and age at menarche in female offspring. Obstet. Gynecol. 101, 529-533. doi: 10.1016/S0029-7844(02) 02718-7

Villar, J., Carroli, G., Wojdyla, D., Abalos, E., Giordano, D., Ba'aqeel, H., et al. (2006). Preeclampsia, gestational hypertension and intrauterine growth restriction, related or independent conditions? Am. J. Obstet. Gynecol. 194, 921-931. doi: 10.1016/j.ajog.2005.10.813

Von Versen-Hoynck, F., Rajakumar, A., Bainbridge, S. A., Gallaher, M. J., Roberts, J M., and Powers, R. W. (2009). Human placental adenosine receptor expression is elevated in preeclampsia and hypoxia increases expression of the $\mathrm{A} 2 \mathrm{~A}$ receptor. Placenta 30, 434-442. doi: 10.1016/j.placenta.2009.02.004

Wadsack, C., Desoye, G., and Hiden, U. (2012). The feto-placental endothelium in pregnancy pathologies. Wien. Med. Wochenschr. 162, 220-224. doi: $10.1007 / \mathrm{s} 10354-012-0075-2$
Wu, C. S., Nohr, E. A., Bech, B. H., Vestergaard, M., Catov, J. M., and Olsen, J. (2009). Health of children born to mothers who had preeclampsia: a population-based cohort study. Am. J. Obstet. Gynecol. 201, 269.e1-269.e10. doi: 10.1016/j.ajog.2009.06.060

Wu, C. S., Nohr, E. A., Bech, B. H., Vestergaard, M., Catov, J. M., and Olsen, J. (2011). Diseases in children born to mothers with preeclampsia: a populationbased sibling cohort study. Am. J. Obstet. Gynecol. 204, 157.e1-157.e5. doi: 10.1016/j.ajog.2010.08.046

Wyatt, A. W., Steinert, J. R., Wheeler-Jones, C. P., Morgan, A. J., Sugden, D., Pearson, J. D., et al. (2002). Early activation of the p42/p44MAPK pathway mediates adenosine-induced nitric oxide production in human endothelial cells: a novel calcium-insensitive mechanism. FASEB J. 16, 1584-1594. doi: 10.1096/fj.01-0125com

Xia, L., Zhou, X. P., Zhu, J. H., Xie, X. D., Zhang, H., Wang, X. X., et al. (2007). Decrease and dysfunction of endothelial progenitor cells in umbilical cord blood with maternal pre-eclampsia. J. Obstet. Gynaecol. Res. 33, 465-474. doi: 10.1111/j.1447-0756.2007.00555.x

Xiong, X., Demianczuk, N. N., Saunders, L. D., Wang, F. L., and Fraser, W. D. (2002). Impact of preeclampsia and gestational hypertension on birth weight by gestational age. Am. J. Epidemiol. 155, 203-209. doi: 10.1093/aje/155.3.203

Xu, M. H., Gong, Y. S., Su, M. S., Dai, Z. Y., Dai, S. S., Bao, S. Z., et al. (2011). Absence of the adenosine A2A receptor confers pulmonary arterial hypertension and increased pulmonary vascular remodeling in mice. J. Vasc. Res. 48, 171-183. doi: 10.1159/000316935

Yoneyama, Y., Sawa, R., Suzuki, S., Otsubo, Y., Miura, A., Kuwabara, Y., et al. (2002a). Serum adenosine deaminase activity in women with pre-eclampsia. Gynecol. Obstet. Invest. 54, 164-167. doi: 10.1159/000067885

Yoneyama, Y., Sawa, R., Suzuki, S., Shin, S., Power, G. G., and Araki, T. (1996). The relationship between uterine artery Doppler velocimetry and umbilical venous adenosine levels in pregnancies complicated by preeclampsia. Am. J. Obstet. Gynecol. 174, 267-271. doi: 10.1016/S0002-9378(96)70406-4

Yoneyama, Y., Suzuki, S., Sawa, R., Kiyokawa, Y., Power, G. G., and Araki, T. (2001). Plasma adenosine levels and P-selectin expression on platelets in preeclampsia. Obstet. Gynecol. 97, 366-370. doi: 10.1016/S0029-7844(00)01184-4

Yoneyama, Y., Suzuki, S., Sawa, R., Takeuchi, T., Kobayashi, H., Takei, R., et al. (2000). Changes in plasma adenosine concentrations during normal pregnancy. Gynecol. Obstet. Invest. 50, 145-148. doi: 10.1159/000010313

Yoneyama, Y., Suzuki, S., Sawa, R., Yoneyama, K., Power, G. G., and Araki, T. (2002b). Increased plasma adenosine concentrations and the severity of preeclampsia. Obstet. Gynecol. 100, 1266-1270. doi: 10.1016/S0029-7844(02)02247-0

Yoneyama, Y., Suzuki, S., Sawa, R., Yoneyama, K., Power, G. G., and Araki, T. (2002c). Relation between adenosine and T-helper 1/T-helper 2 imbalance in women with preeclampsia. Obstet. Gynecol. 99, 641-646. doi: 10.1016/S0029-7844(02)01657-5

Yu, X. D., Branch, D. W., Karumanchi, S. A., and Zhang, J. (2012). Preeclampsia and retinopathy of prematurity in preterm births. Pediatrics 130, e101-e107. doi: $10.1542 /$ peds.2011-3881

Conflict of Interest Statement: The authors declare that the research was conducted in the absence of any commercial or financial relationships that could be construed as a potential conflict of interest.

Received: 13 March 2014; accepted: 16 May 2014; published online: 05 June 2014. Citation: Escudero C, Roberts JM, Myatt L and Feoktistov I (2014) Impaired adenosinemediated angiogenesis in preeclampsia: potential implications for fetal programming. Front. Pharmacol. 5:134. doi: 10.3389/fphar.2014.00134

This article was submitted to Cardiovascular and Smooth Muscle Pharmacology, a section of the journal Frontiers in Pharmacology.

Copyright (C) 2014 Escudero, Roberts, Myatt and Feoktistov. This is an open-access article distributed under the terms of the Creative Commons Attribution License (CC BY). The use, distribution or reproduction in other forums is permitted, provided the original author(s) or licensor are credited and that the original publication in this journal is cited, in accordance with accepted academic practice. No use, distribution or reproduction is permitted which does not comply with these terms. 